\title{
Insights into oxygen transport and net community production in sea ice from oxygen, nitrogen and argon concentrations
}

\author{
J. Zhou ${ }^{1,2}$, B. Delille ${ }^{2}$, F. Brabant ${ }^{1}$, and J.-L. Tison ${ }^{1}$ \\ ${ }^{1}$ Laboratoire de glaciologie, DSTE, Université Libre de Bruxelles, Brussels, Belgium \\ ${ }^{2}$ Unité d'Océanographie chimique, MARE, Université de Liège, Liège, Belgium \\ Correspondence to: J. Zhou (jiayzhou@ulb.ac.be)
}

Received: 20 December 2013 - Published in Biogeosciences Discuss.: 4 February 2014 Revised: 11 August 2014 - Accepted: 18 August 2014 - Published: 18 September 2014

\begin{abstract}
We present and compare the dynamics (i.e., changes in standing stocks, saturation levels and concentrations) of $\mathrm{O}_{2}, \mathrm{Ar}$ and $\mathrm{N}_{2}$ in landfast sea ice, collected in Barrow (Alaska), from February through June 2009. The comparison suggests that the dynamic of $\mathrm{O}_{2}$ in sea ice strongly depends on physical processes (gas incorporation and subsequent transport). Since $\mathrm{Ar}$ and $\mathrm{N}_{2}$ are only sensitive to the physical processes in the present study, we then discuss the use of $\mathrm{O}_{2} / \mathrm{Ar}$ and $\mathrm{O}_{2} / \mathrm{N}_{2}$ to correct for the physical contribution to $\mathrm{O}_{2}$ supersaturations, and to determine the net community production (NCP). We conclude that $\mathrm{O}_{2} / \mathrm{Ar}$ suits better than $\mathrm{O}_{2} / \mathrm{N}_{2}$, due to the relative abundance of $\mathrm{O}_{2}, \mathrm{~N}_{2}$ and $\mathrm{Ar}$, and the lower biases when gas bubble formation and gas diffusion are maximized. We further estimate NCP in the impermeable layers during ice growth, which ranged from -6.6 to $3.6 \mu \mathrm{mol} \mathrm{O}_{2} \mathrm{~L}^{-1} \mathrm{~d}^{-1}$, and the concentrations of $\mathrm{O}_{2}$ due to biological activity in the permeable layers during ice decay (3.8 to $122 \mu \mathrm{mol} \mathrm{O}_{2} \mathrm{~L}^{-1}$ ). We finally highlight the key issues to solve for more accurate NCP estimates in the future.
\end{abstract}

\section{Introduction}

Sea ice is a composite material with a matrix of pure ice and inclusions of brine (Weeks, 2010). The latter concentrates most of the impurities of the ice, including dissolved compounds, gas bubbles, and micro-organisms that are able to survive at high salinities and low temperatures (Thomas and Dieckmann, 2002). The net community production (NCP), i.e., the net carbon fixation due to photosynthesis and respiration of the microorganisms in sea ice is a crucial measurement in polar ecological studies, because it is generally the sole source of fixed carbon for the higher trophic-level species in ice-covered oceans (Arrigo et al., 2010; Brierley and Thomas, 2002; Michel et al., 1996).

However, the measurement of NCP in sea ice is challenging due to the composite structure of sea ice. A traditional standard technique is to measure the accumulation of algal biomass and its temporal change via the measurements of chlorophyll $a$ (chl $a$ ) or particulate organic carbon (POC). Another traditional standard technique is to measure the maximum photosynthetic rate and photosynthetic efficiency in a laboratory, and then to deduce the changes of biomass based on the concentration of chl $a$ and the light intensity from the field, assuming that the photosynthetic parameters obtained in laboratory still hold for field measurements. Both standard techniques have one major limitation: they require the extraction and the melting of sea ice, which inevitably alters the growth environment of the microorganisms (e.g., sudden change of brine salinity due to bulk ice melting).

The more recent techniques for NCP measurement favor in situ measurements with minimized disturbance on sea ice. These include pulse amplitude modulated (PAM) fluorometry (Glud et al., 2002), $\mathrm{O}_{2}$ micro-electrodes (McMinn and Ashworth, 1998), $\mathrm{O}_{2}$ micro-optodes (Mock et al., 2002) and ice-water interface $\mathrm{O}_{2}$ eddy correlation (Long et al., 2012). Nonetheless, the results still depend on the composite structure and the physical properties of sea ice(i.e., permeability and brine dynamics). For instance, the PAM fluorescence depends on the spatial distribution of the algal biomass and the optical properties of the ice (Glud et al., 2002). Another example is that the amount of $\mathrm{O}_{2}$ measured using microsensors depends on whether the sensors were set in brine, ice, gas 
bubbles or bacterial films (Mock et al., 2002) and whether the ice permeability allows the diffusion of $\mathrm{O}_{2}$ to the microsensors (Glud et al., 2002). Although the ice-water $\mathrm{O}_{2}$ eddy correlation seems promising, because of its large footprint in comparison to the other techniques, it may be sensitive to the additional input of $\mathrm{O}_{2}$ from sea ice due to brine convection and ice melt (Long et al., 2012). In that context, understanding the dynamics of $\mathrm{O}_{2}$ within the ice will better constrain the $\mathrm{O}_{2}$ fluxes at the ice-water interface, obtained from eddy correlation.

The present study first aims to describe the dynamics of $\mathrm{O}_{2}$ in sea ice, based on a time series of $\mathrm{O}_{2}$ concentrations within sea ice from ice growth to ice decay. The $\mathrm{O}_{2}$ measurements were obtained from ice crushing, which allows the measurement of both dissolved and gaseous $\mathrm{O}_{2}$ (i.e., $\mathrm{O}_{2}$ in brine and gas bubbles), in both permeable and impermeable sea ice layers (i.e., ice layer with brine volume fraction above and below $5 \%$ respectively; Golden et al., 1998). Since current studies have mainly focused on the dissolved $\mathrm{O}_{2}$ in the permeable ice layers (Glud et al., 2002; Mock et al., 2002), our study undeniably extends the current knowledge on $\mathrm{O}_{2}$ dynamic.

Second, as it is well known that gas diffusion and brine convection affect the measured $\mathrm{O}_{2}$ concentrations in sea ice (e.g., Glud et al., 2002; Long et al., 2012), we will also discuss the possibility of correcting the imprints of these physical processes on $\mathrm{O}_{2}$, using nitrogen $\left(\mathrm{N}_{2}\right)$ and argon (Ar) and to determine NCP. Some recent studies yielded the NCP in seawater from the measurements of ratio (Cassar et al., 2009; Castro-Morales et al., 2013; Hendricks et al., 2004; Reuer et al., 2007), while others have proven that $\mathrm{O}_{2} / \mathrm{N}_{2}$ was sensitive to the biological activity in basal continental ice (e.g., Souchez et al., 2006). These approaches consider Ar and $\mathrm{N}_{2}$ as inert to biogeochemical processes (hence, not affected by $\mathrm{NCP}$ ), where the use of $\mathrm{O}_{2} / \mathrm{Ar}$ and $\mathrm{O}_{2} / \mathrm{N}_{2}$ ratios allows for the correction of physical processes (e.g., temperature, salinity or pressure changes and bubble effects).

\section{Materials and methods}

\subsection{Sampling area and sampling events}

The ice cores were collected on landfast sea ice, off the coast of Barrow (Fig. 1), from January through June 2009. The sampling area covered a surface of $50 \mathrm{~m} \times 50 \mathrm{~m}$. The northeastern corner of the square was located at $71^{\circ} 22.013^{\prime} \mathrm{N}$, $156^{\circ} 32.447^{\prime} \mathrm{W}$. The ice cores were extracted by drilling and then stored at $-30^{\circ} \mathrm{C}$ in the dark, to prevent brine drainage and to limit biological activity. All of the analyses were completed within the following year. The physical framework has been presented and discussed in Zhou et al. (2013). In brief, all of the ice cores had similar crystallographic structure, with a dominance of columnar ice that suggests low spatial variability.

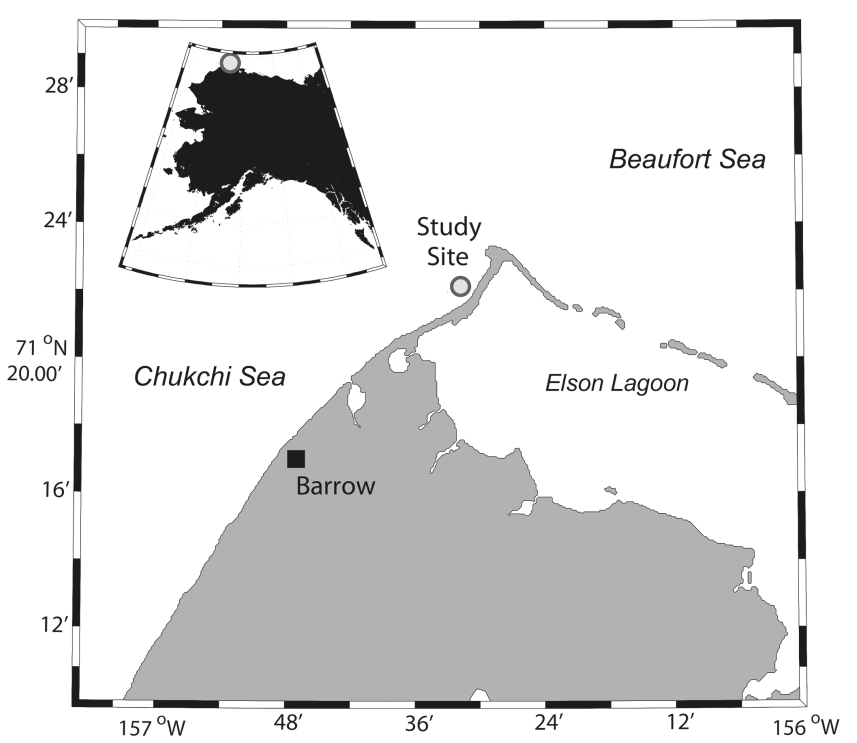

Figure 1. The study site, north of Barrow (Alaska, USA).

In the present paper, five sampling events (out of 10) were selected to illustrate the temporal evolution of chl $a, \mathrm{O}_{2}$, $\mathrm{O}_{2} / \mathrm{Ar}$ and $\mathrm{O}_{2} / \mathrm{N}_{2}$ at our location: one in winter (BRW2 - 3 February), two in early spring (BRW4, BRW7 - corresponding to 31 March and 10 April respectively), one in mid spring (BRW8 - 8 May), and the last one in late spring (BRW10 - 5 June). The first four sampling events occurred during ice growth, the last one during ice decay. As discussed in Zhou et al. (2013), full-depth convection occurred in BRW8, leading to the drainage of the dissolved compounds in brine, and a partial replenishment by seawater. This contrasted with the sampling events prior to BRW8, where convection only occurred in the permeable bottom ice layers. Finally, in BRW10, the increase of air temperature led to ice melt, full permeability, brine stratification, and the formation of $20 \mathrm{~cm}$ of superimposed ice at the surface of the ice. The formation of superimposed ice indicates that seeping snow meltwater had frozen on contact with sea ice (Haas et al., 2001) .

\subsection{Chlorophyll $a$ and phaeopigment}

The ice samples were melted in the dark, in $0.2 \mu \mathrm{m}$ filtered seawater (1:4 volume ratio) to avoid osmotic stress. We used 10 and $0.8 \mu \mathrm{m}$ polycarbonate filters in a sequence in order to distinguish larger micro-algae species from the smaller ones. Extractions and calculations were made following the procedure of Arar and Collins (1997). The standing stocks of chlorophyll $a$ (chl $a$ ) were calculated by integrating the chl $a$ concentrations over the whole ice length and have been discussed in Zhou et al. (2013). The percentage of phaeopigment was obtained by dividing the concentration of phaeopigment by the sum of both chl $a$ and phaeopigment concentrations. As phaeopigments result from chl $a$ 
degradation, a high percentage of phaeopigments indicates strong grazing pressure, and/or high algal mortality.

\section{3 $\mathrm{O}_{2}, \mathrm{Ar}$ and $\mathrm{N}_{2}$ concentrations in ice and their respective solubility}

We used the dry-crushing technique developed for gas measurements in continental ice (Raynaud et al., 1982) to extract $\mathrm{O}_{2}, \mathrm{Ar}$ and $\mathrm{N}_{2}$ from the ice samples. This technique extracts the gas bubbles in the ice and the gas in the dissolved state within liquid brine. Each ice core was cut every $5 \mathrm{~cm}$, and about $60 \mathrm{~g}$ of sample was introduced into a vessel, with seven stainless steel balls. The ice was crushed in the vessel, under a vacuum $\left(10^{-3}\right.$ torr $)$, as described in Stefels et al. (2012) at $-25^{\circ} \mathrm{C}$. Subsequently, the vessel was kept at $-50^{\circ} \mathrm{C}$ in a cold ethanol bath, and was connected to the gas chromatograph equipped with a thermal conductivity detector for concentration analyses (Skoog et al., 1997). We used Alphagaz $^{\mathrm{TM}} 2-\mathrm{He}$ (Air Liquide - P0252) as carrier gas and a $22 \mathrm{ml}$ packed column (Mole Sieve 5A 80/100; $5 \mathrm{~m} \times 1 / 8 \mathrm{in}$.). The reproducibility of the analyses (i.e., the precision of the gas chromatograph) was $99.3 \%$ for $\mathrm{O}_{2}, 97.8 \%$ for $\mathrm{Ar}$ and $99.9 \%$ for $\mathrm{N}_{2}$. It corresponds to $100 \%$ minus the variation coefficient (in \%) obtained from triplicate analysis of four different standards (2, 3, 5, 10 torr of injection pressures). In addition, diel $\mathrm{O}_{2}$ production/respiration may account for 3 to $6 \%$ of variations in our $\mathrm{O}_{2}$ concentrations, as all the ice cores were not sampled at the same time of the day; more details on the error estimates are given in the Supplement S1.

To compute the saturation levels (i.e., the deviation from saturation) of $\mathrm{O}_{2}, \mathrm{Ar}$ and $\mathrm{N}_{2}$ in ice and for further calculations (Sects. 2.4 and 2.5), we also determined the theoretical solubility of each gas in ice at saturation. The solubility in the brine was calculated using temperature and salinity, following the relationship of Garcia and Gordon (1992) for $\mathrm{O}_{2}$ and the relationship of Hamme and Emerson (2004) for $\mathrm{N}_{2}$ and Ar. This value weighted by the brine volume fraction constitutes the solubility in ice. Weighting is necessary, as most of the impurities (including gases) are concentrated within the brine structure, but not in the pure ice matrix (Weeks, 2010). It is noteworthy that the relationship of Hamme and Emerson (2004) was established for temperatures between 0 and $30^{\circ} \mathrm{C}$ and salinities between 0 and 34.5, and the relationship of Garcia and Gordon (1992) for temperatures between 0 and $40^{\circ} \mathrm{C}$ and salinities between 0 and 42 . We thus assumed in our calculations of gas solubility that those relationships still hold for the range of temperature and salinity found in our brine samples.

Gas saturation levels are described following Craig and Hayward (1987) for seawater as follows:

$\Delta C_{\mathrm{i}}=\frac{C_{\mathrm{i}}}{C_{\mathrm{eq}}}-1$,

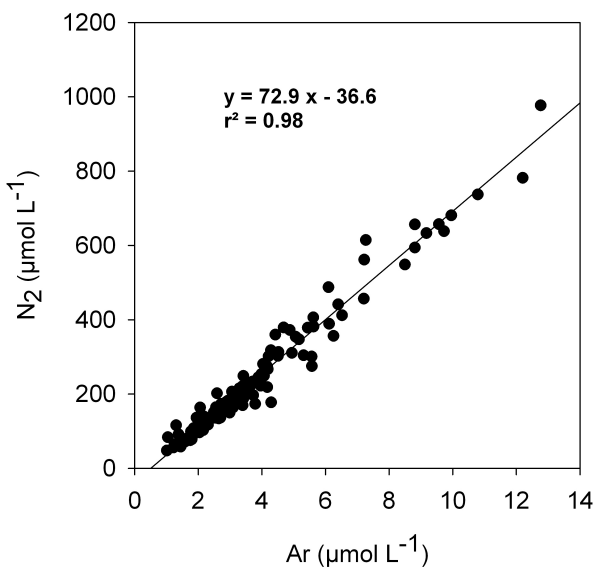

Figure 2. Concentrations of $\mathrm{N}_{2}$ in ice plotted against the concentrations of $\mathrm{Ar}$ in ice. The equation and $r^{2}$ are calculated assuming a linear regression between both gas concentrations.

where $C_{i}$ is the measured concentration of the gas $i$ in bulk ice and $C_{\text {eq }}$ the solubility of gas $i$ in bulk ice at equilibrium with the atmosphere, calculated at in situ temperature, salinity and pressure as described above. Note that for comparison with the literature, gas saturations are given in percentage in the text. Supersaturation and undersaturation are therefore represented by positive and negative percentage values respectively.

\section{$2.4 \mathrm{O}_{2} / \mathrm{Ar}$ and $\mathrm{O}_{2} / \mathrm{N}_{2}$}

The use of $\mathrm{O}_{2} / \mathrm{Ar}$ and $\mathrm{O}_{2} / \mathrm{N}_{2}$ is only valid if both $\mathrm{Ar}$ and $\mathrm{N}_{2}$ are inert. Ar is a noble gas, i.e., inert and not affected by any biogeochemical processes. $\mathrm{N}_{2}$ is affected by denitrification, which was found to occur in sea ice (Rysgaard et al., 2008), but whose impact on $\mathrm{N}_{2}$ concentrations should be negligible in the present study. The maximum reported denitrification rate $\left(23 \mathrm{nmol} \mathrm{N}_{2} \mathrm{~L}^{-1} \mathrm{~d}^{-1}\right)$ was 4 orders of magnitude lower than the average bulk ice $\mathrm{N}_{2}$ concentrations $\left(248 \mu \mathrm{mol} \mathrm{N}_{2} \mathrm{~L}^{-1}\right)$ presented here. The correlation between $\mathrm{N}_{2}$ and Ar with a $r^{2}$ of 0.98 (Fig. 2) further supports that $\mathrm{N}_{2}$ can be treated as inert like Ar, and used to trace physical processes.

$\mathrm{O}_{2} / \mathrm{Ar}$ and $\mathrm{O}_{2} / \mathrm{N}_{2}$ ratios were calculated from the concentrations of $\mathrm{O}_{2}, \mathrm{Ar}$ and $\mathrm{N}_{2}$ in ice, and were compared with their respective ratios in seawater and the atmosphere. The relative solubility of $\mathrm{O}_{2} / \mathrm{Ar}$ in seawater $\left(\right.$ at $0^{\circ} \mathrm{C}$, with 32 of salinity) is 20.48 (Garcia and Gordon, 1992; Hamme and Emerson, 2004). However, even in abiotic conditions, the gas ratios in sea ice after gas incorporation and before sea ice consolidation (i.e., being impermeable) may differ from that in seawater due to diffusion process at the ice/seawater interface (Killawee et al., 1998; Tison et al., 2002). We thus applied the relative diffusion coefficient of $\mathrm{O}_{2}$ and $\mathrm{Ar}(1.2 / 0.8$ $=1.5$ ) (Broecker and Peng, 1982) to our relative solubility of $\mathrm{O}_{2}$ / Ar to obtain a value of $\mathrm{O}_{2} / \mathrm{Ar}$ with maximized diffusion 
Table 1. Diffusion coefficients of $\mathrm{O}_{2}, \mathrm{Ar}$ and $\mathrm{N}_{2}$ found in the literature for different medium (water, seawater and sea ice) for temperature at or below $0^{\circ} \mathrm{C}$. Salinity is given when available. The diffusion coefficients in use in the present study are those of Broecker and Peng (1982) (in bold).

\begin{tabular}{lllllll}
\hline & Medium & $\begin{array}{l}\text { Temperature } \\
{ }^{\circ} \mathrm{C}\end{array}$ & Salinity & $\begin{array}{l}\mathrm{O}_{2} \\
10^{-5} \mathrm{~cm}^{2} \mathrm{~s}^{-1}\end{array}$ & $\begin{array}{l}\text { Ar } \\
10^{-5} \mathrm{~cm}^{2} \mathrm{~s}^{-1}\end{array}$ & $\begin{array}{l}\mathrm{N}_{2} \\
10^{-5} \mathrm{~cm}^{2} \mathrm{~s}^{-1}\end{array}$ \\
\hline $\begin{array}{l}\text { Broecker and Peng (1974) } \\
\text { Broecker and Peng (1982) }\end{array}$ & Water & 0 & $?$ & 1.17 & 0.88 & 0.95 \\
$\begin{array}{l}\text { Ferrell and Himmelblau (1967), } \\
\text { Jähne et al. (1987) }\end{array}$ & Seawater & $\mathbf{0}$ & $\mathbf{?}$ & $\mathbf{1 . 2}$ & $\mathbf{0 . 8}$ & $\mathbf{1 . 1}$ \\
$\begin{array}{l}\text { Loose et al. (2010) } \\
\text { Crabeck et al. (2014) }\end{array}$ & Ice & -12 to -4 & $3.78-6.58$ & 3.9 & - & 0.94 \\
\hline
\end{tabular}

${ }^{1}$ Computed solubility using the matlab code available on http://web.uvic.ca/ rhamme/download.html.

2 The values are gas diffusivities which should take into account the geometry of the brine structure.

processes at the bottom of sea ice (13.65) as described below. Note that different diffusion coefficients exist in the literature (Table 1) for temperature close to $0^{\circ} \mathrm{C}$ or below, for seawater, water or ice; we chose to use the diffusion coefficients of Broecker and Peng (1982) because it is the most recent peer-reviewed study that provides diffusion coefficients for $\mathrm{O}_{2}, \mathrm{Ar}$ and $\mathrm{N}_{2}$ near the freezing temperature. Salinity is not given in Broecker and Peng (1982), but one may expect a maximum decrease of $4.9 \%$ of the diffusion coefficient per 35.5 of salinity increase (Jähne et al., 1987).

The initial values of $\mathrm{O}_{2} / \mathrm{Ar}$ could range between 13.65 and 20.48, based on the magnitude of gas diffusion at the ice/seawater interface. Further, as $\mathrm{O}_{2} / \mathrm{Ar}$ in the atmosphere is 22.5, gas input from the atmosphere (during frazil ice formation or when sea ice is permeable) and gas bubble formation in the permeable ice should pull the bulk ice $\mathrm{O}_{2} / \mathrm{Ar}$ towards 22.50. Therefore, if both dissolved and gaseous states exist in the ice, $\mathrm{O}_{2} / \mathrm{Ar}$ could range between 13.65 and 22.50 due to physical processes, hereafter referred to abiotic range of $\mathrm{O}_{2} / \mathrm{Ar}$.

We applied the same calculation to $\mathrm{O}_{2} / \mathrm{N}_{2}$. The relative solubility in seawater is 0.56 (Garcia and Gordon, 1992; Hamme and Emerson, 2004). Since the relative diffusion coefficient between $\mathrm{O}_{2}$ and $\mathrm{N}_{2}$ is 1.09 (Broecker and Peng, 1982), the relative solubility with maximized diffusion processes is 0.51 . Given that the atmospheric ratio of $\mathrm{O}_{2} / \mathrm{N}_{2}$ is 0.27 , the abiotic range of $\mathrm{O}_{2} / \mathrm{N}_{2}$ in ice is $0.27-0.51 . \mathrm{O}_{2} / \mathrm{N}_{2}$ that is above or below this abiotic range is attributed to an impact of biological activity (Souchez et al., 2006).

\subsection{Deviation of the $\mathrm{O}_{2} / \mathrm{Ar}$ from saturation}

The deviation of $\mathrm{O}_{2} / \mathrm{Ar}$ from saturation, $\Delta\left(\mathrm{O}_{2} / \mathrm{Ar}\right.$ ) (which is referred to as "biological $\mathrm{O}_{2}$ supersaturation" in seawater studies, e.g., Castro-Morales et al., 2013), is formulated as in Eq. (2), and we define the $\mathrm{O}_{2}$ concentrations associated with the in situ biological activity $\left(\left[\mathrm{O}_{2}\right]_{\text {bio }}\right)$ as in Eq. (3):

$\Delta\left(\mathrm{O}_{2} / \mathrm{Ar}\right)=\frac{\left[\mathrm{O}_{2}\right] /[\mathrm{Ar}]}{\left[\mathrm{O}_{2}\right]_{\mathrm{eq}} /[\mathrm{Ar}]_{\mathrm{eq}}}-1$
$\left[\mathrm{O}_{2}\right]_{\text {bio }}=\left[\mathrm{O}_{2}\right]_{\mathrm{eq}} \Delta\left(\mathrm{O}_{2} / \mathrm{Ar}\right)$.

For seawater, $\left[\mathrm{O}_{2}\right]_{\mathrm{eq}}$ and $[\mathrm{Ar}]_{\mathrm{eq}}$ are respectively the solubility of $\mathrm{O}_{2}$ and $\mathrm{Ar}$ at saturation. In ice, however, $\left[\mathrm{O}_{2}\right]_{\mathrm{eq}}$ and $[\mathrm{Ar}]_{\mathrm{eq}}$ may differ from these solubilities due to physical processes such as bubble nucleation, diffusion and convection (see Sects. 2.4 and 4.6).

Multiplying the $\left[\mathrm{O}_{2}\right]_{\text {bio }}$ obtained in Eq. (3) (in $\mathrm{molO}_{2} \mathrm{~L}^{-1}$ ) by the ice thickness of the samples (generally $5 \mathrm{~cm}$ ) gives a production of $\mathrm{O}_{2}$ in $\mathrm{mol} \mathrm{m}^{-2}$. With an $\mathrm{O}_{2} / \mathrm{C}$ ratio of 1.43 (Glud et al., 2002) and the molar mass of $\mathrm{C}$, we can calculate the equivalent $\mathrm{C}$ uptake in $\mathrm{g} \mathrm{C} \mathrm{m}^{-2}$. The change of that $\mathrm{C}$ uptake over time is the NCP. Since NCP is derived from the comparison of $\mathrm{C}$ uptake obtained in distinct ice cores that are separated by a certain time interval, how nutrient and light availability locally affect the $\mathrm{C}$ uptake is not taken into consideration.

\section{Results}

\subsection{A general overview from the standing stocks}

Figure 3 shows the standing stocks of $\mathrm{Ar}, \mathrm{O}_{2}$ and $\mathrm{N}_{2}$, in parallel with the ice thickness, for the different sampling events. $\mathrm{N}_{2}$ has the largest standing stocks among the three gases, followed by $\mathrm{O}_{2}$ and then Ar. The temporal variation of the three gas standing stocks were similar, but differed from that of the ice thickness: while sea ice continuously thickened from BRW2 $(82 \mathrm{~cm})$ to BRW10 $(142 \mathrm{~cm})$, the gas standing stocks increased from BRW2 to BRW8 but decreased at BRW10.

\subsection{Gas saturation levels}

The saturation levels of $\mathrm{N}_{2}, \mathrm{O}_{2}$ and Ar decreased with increasing brine volume fraction (Fig. 4). The highest supersaturation of $\mathrm{N}_{2}, \mathrm{O}_{2}$ and $\mathrm{Ar}(7030,3180$ and $2960 \%$ respectively) corresponded to the lowest brine volume fraction 


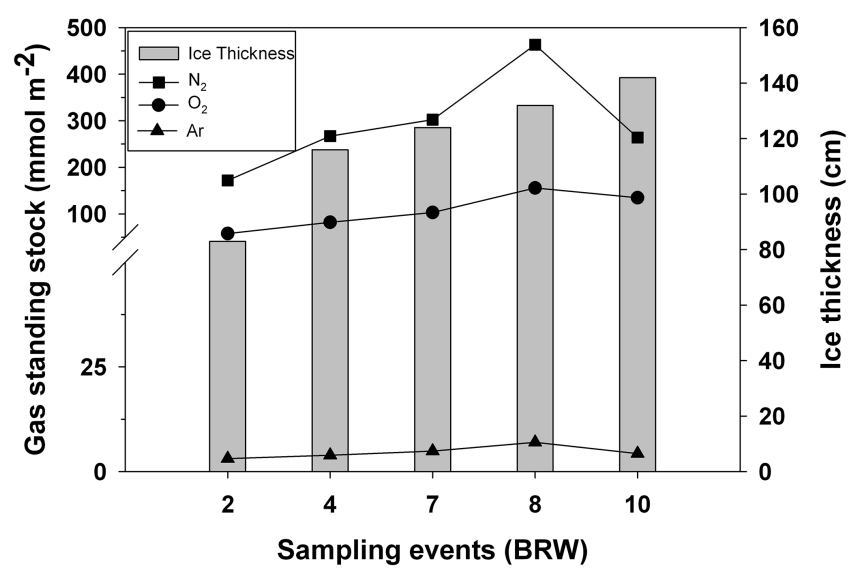

Figure 3. Evolution of the standings stocks of $\mathrm{N}_{2}, \mathrm{O}_{2}$ and $\mathrm{Ar}$ (squares, circles and triangles respectively) compared to the evolution of sea ice thickness (vertical grey bars). The break in gas standing stocks is set at $50 \mathrm{mmol} \mathrm{m}^{-2}$.

$(2.2 \%)$, while the lowest undersaturations $(-33,-52$ and $-54 \%$ respectively) corresponded to the largest brine volume fraction $(29.3 \%)$. In addition, $\mathrm{N}_{2}$ saturation levels contrasted with those of $\mathrm{O}_{2}$ and Ar: for similar brine volume fraction, $\mathrm{N}_{2}$ generally reached higher supersaturation levels than $\mathrm{O}_{2}$ and Ar, which have much similar saturation levels.

\section{$3.3 \mathrm{O}_{2}$ concentrations}

Figure 5a shows the concentration of $\mathrm{O}_{2}$ in bulk ice $\left[\mathrm{O}_{2}\right]$, compared to the solubility of $\mathrm{O}_{2}$ in ice. The dashed areas refer to the permeable ice (i.e., layers with brine volume fraction above $5 \%$, while the non-dashed areas right above refer to the impermeable layers (i.e., with brine volume fraction below $5 \%$ ); Golden et al., 1998). Mean $\left[\mathrm{O}_{2}\right]$ increased from BRW2 $\left(67.4 \mu \mathrm{mol} \mathrm{L}^{-1}\right)$ to BRW8 $\left(122.4 \mu \mathrm{mol} \mathrm{L}^{-1}\right)$ and decreased at BRW10 $\left(93.4 \mu \mathrm{mol} \mathrm{L}^{-1}\right)$. At BRW2 and BRW4, $\left[\mathrm{O}_{2}\right]$ generally exceeded the solubility of $\mathrm{O}_{2}$ in the impermeable layers, but reached the solubility values in the permeable layers. The trends changed from BRW7 onwards: in BRW7 and BRW8, $\left[\mathrm{O}_{2}\right]$ was higher than the solubility at all depths, except in the 5 last centimeters of the ice core. In BRW10, $\left[\mathrm{O}_{2}\right]$ was close to the solubility of $\mathrm{O}_{2}$ in the upper layers (from 12.5 to $72.5 \mathrm{~cm}$ ), but exceeded the solubility of $\mathrm{O}_{2}$ below these layers.

\subsection{Chlorophyll $a$ and phaeopigment concentrations}

The concentrations of $\operatorname{chl} a$ [chl $a$ ] varied largely with depth (Fig. 5b) and ranged from 0 to $83.9 \mu \mathrm{L} \mathrm{L}^{-1}$ over all the sampling events. The highest [chl $a$ ] values were always in the ice bottom, except in BRW4. Above the bottom layer, the [chl $a$ ] was generally below $1 \mu \mathrm{g} \mathrm{L}{ }^{-1}$. Drastic changes occurred in BRW8 when sea ice permeability increased sharply: [chl $a$ ] dropped at all depths, and particularly in the ice interior.

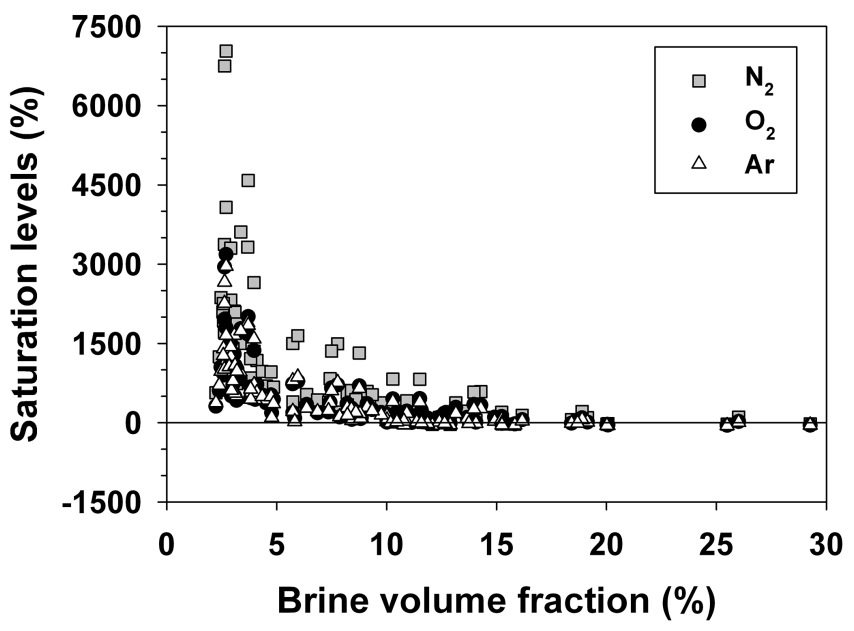

Figure 4. Saturation levels ( $\Delta C_{i}$ in Eq. 1, in percentage) of $\mathrm{N}_{2}, \mathrm{O}_{2}$ and $\mathrm{Ar}$ (squares, circles and triangles respectively) compared to the brine volume fraction.

[chl $a$ ] increased again at BRW10, showing a vertical profile and standings stocks similar to those of BRW7.

The percentage of phaeopigment also varied strongly with depth in BRW2, with over $60 \%$ of phaeopigments in the upper ice layers but less than $20 \%$ at the ice bottom. It varied between 20 and $40 \%$ in BRW4 and BRW7, and increased drastically in BRW8 (with phaeopigments reaching $100 \%$ in some layers). In BRW10, the percentage of phaeopigments varied between about 40 and $70 \%$, with generally higher values in the upper ice layers.

\section{$3.5 \mathrm{O}_{2} / \mathrm{Ar}$ and $\mathrm{O}_{2} / \mathrm{N}_{2}$}

$\mathrm{O}_{2} / \mathrm{Ar}$ in ice ranged between 15.8 and 97.6 (Fig. 5c) and $\mathrm{O}_{2} / \mathrm{N}_{2}$, between 0.3 and 1.5 (Fig. 5d). Both $\mathrm{O}_{2} / \mathrm{Ar}$ and $\mathrm{O}_{2} / \mathrm{N}_{2}$ ratios are compared to their respective values in the atmosphere (22.5 and 0.3) and in seawater with maximized diffusion processes (13.7 and 0.5).

$\mathrm{O}_{2} / \mathrm{Ar}$ in ice at BRW2 was highly homogeneous at all depths, with a mean and standard deviation of $18.49 \pm 0.84$. These ratios were found between the value of $\mathrm{O}_{2} / \mathrm{Ar}$ in the atmosphere and that in seawater with maximized diffusion processes. Over the next sampling events, $\mathrm{O}_{2} / \mathrm{Ar}$ in ice increased on average, exceeding the $\mathrm{O}_{2} / \mathrm{Ar}$ in the atmosphere (the upper limit of $\mathrm{O}_{2} / \mathrm{Ar}$ that can be explained by abiotic processes), and became more variable vertically (Fig. 5c). It is also noteworthy that from BRW4 onwards, the maximum $\mathrm{O}_{2} / \mathrm{Ar}$ in each sampling event was found in the lower part of the ice, but never coincided with the maximum of [chl $a$ ], even at BRW10 where the whole profile of $\mathrm{O}_{2} /$ Ar clearly mimicked the one of [chl $a]$.

Although both $\mathrm{O}_{2} / \mathrm{N}_{2}$ and $\mathrm{O}_{2} / \mathrm{Ar}$ in ice have similar coefficient of variation (respectively, 49 and $46 \%, n=121$ ), $\mathrm{O}_{2} / \mathrm{N}_{2}$ only exceeded once its abiotic range between BRW2 and $\mathrm{BRW} 8$, while $\mathrm{O}_{2} / \mathrm{Ar}$ exceeded its abiotic range from 

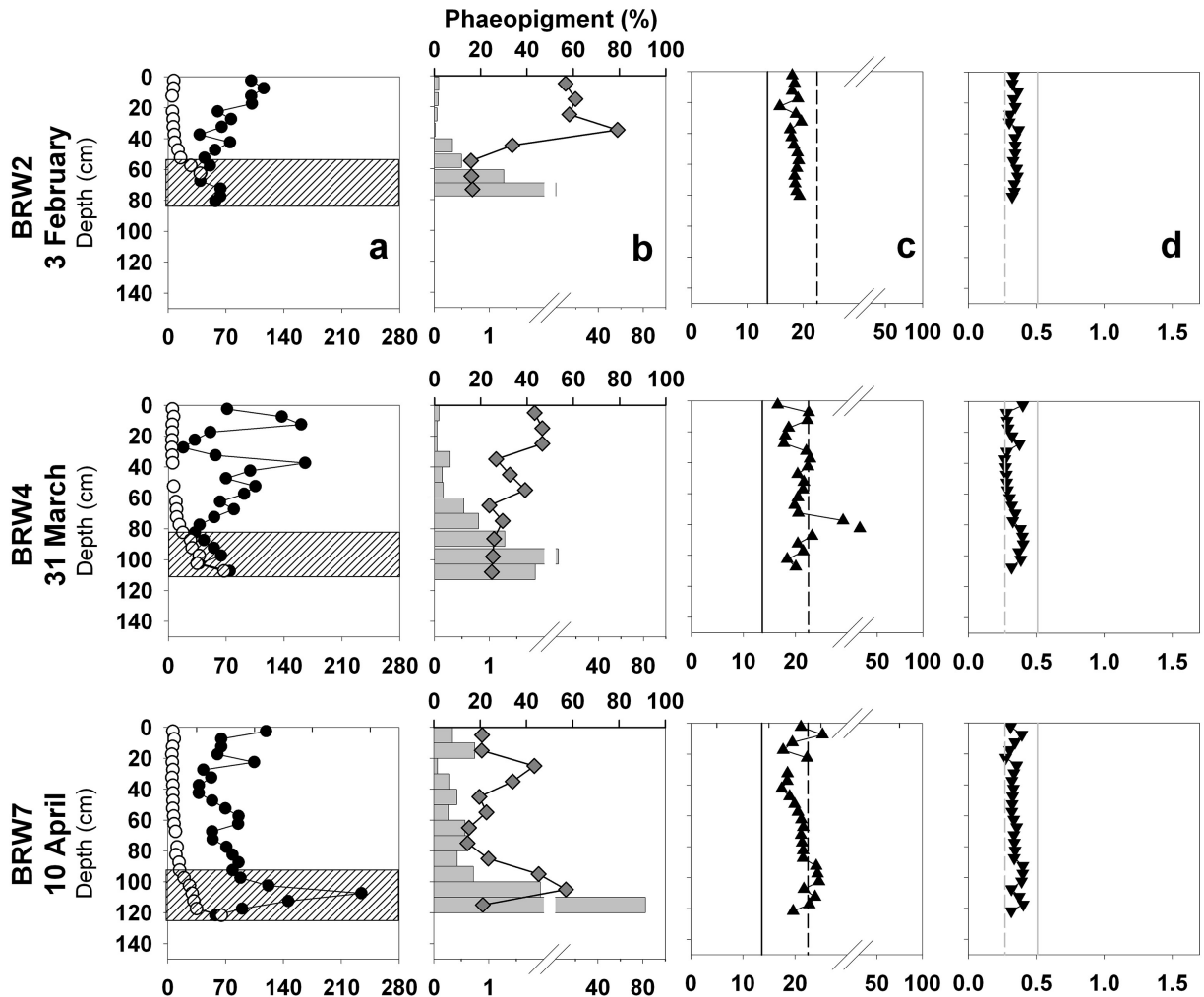

$\begin{array}{llllll}0 & 20 & 40 & 60 & 80 & 100\end{array}$
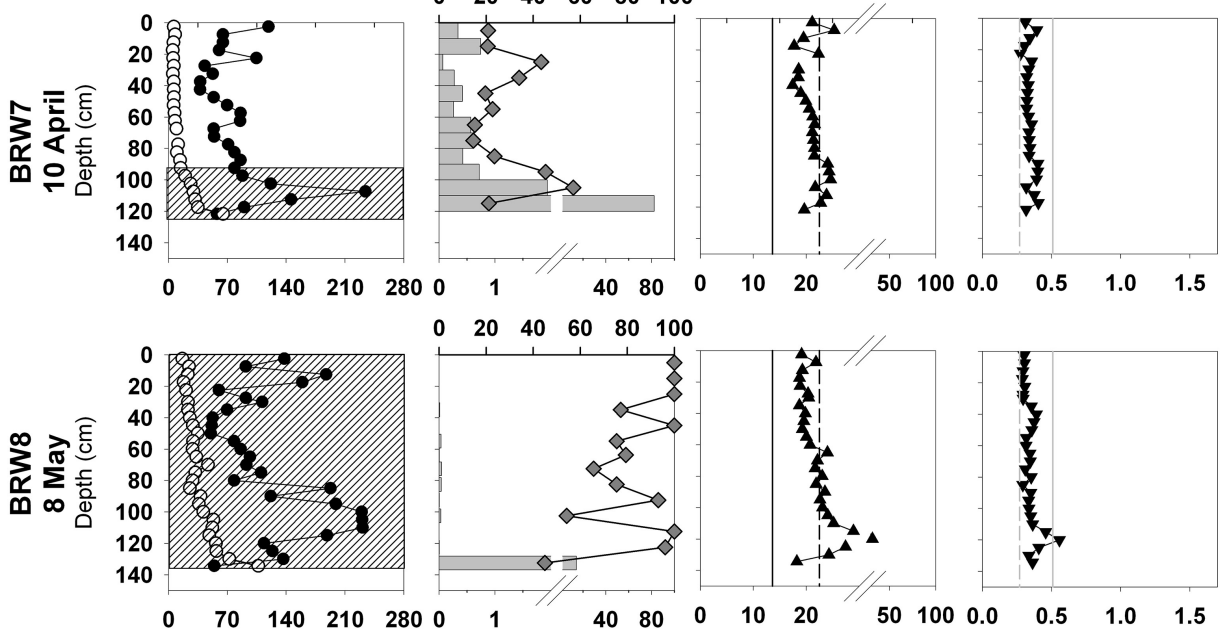

$\begin{array}{llllll}0 & 20 & 40 & 60 & 80 & 100\end{array}$
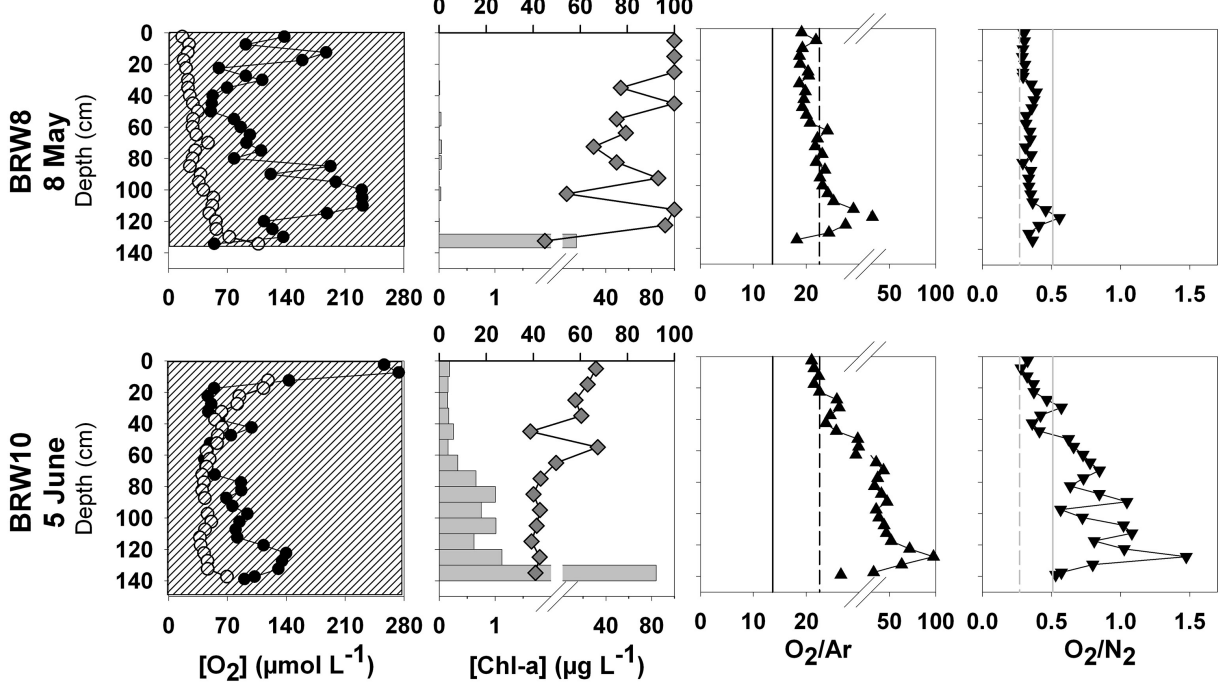

$\begin{array}{llllll}0 & 20 & 40 & 60 & 80 & 100\end{array}$
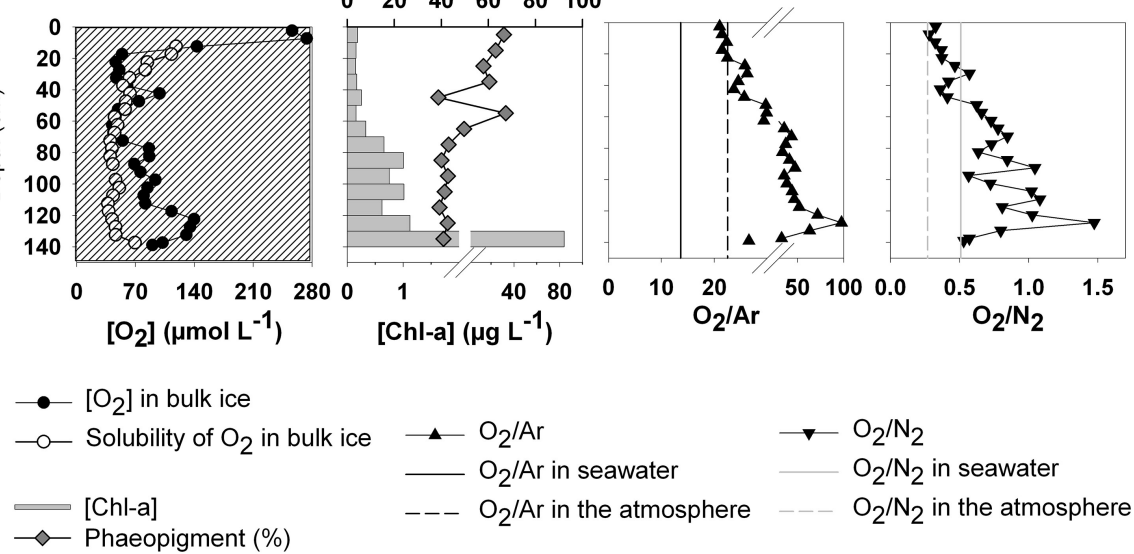

Figure 5. (a) $\mathrm{O}_{2}$ concentration in bulk ice (black dots) compared to its solubility in ice (white dots), the dashed areas refer to permeable ice layers (i.e., with a brine volume fraction above $5 \%$ ); (b) chl $a$ concentrations in ice(horizontal bars) with a break at $2 \mu \mathrm{g} \mathrm{L}-1$ compared to the percentage of phaeopigments (diamonds); (c) $\mathrm{O}_{2} / \mathrm{Ar}$ in ice (upside triangles) with a break at 25, compared to the same ratios in seawater (straight black line) and in the atmosphere (dashed black line); (d) $\mathrm{O}_{2} / \mathrm{N}_{2}$ in ice (downside triangles) compared the same ratios in seawater (straight grey line) and in the atmosphere (dashed grey line). 
BRW4 onwards (Fig. 5c, d). Similarities between $\mathrm{O}_{2} / \mathrm{Ar}$ and $\mathrm{O}_{2} / \mathrm{N}_{2}$ became more obvious in BRW10: both ratios were close to their respective atmospheric values at the ice surface, and they exceeded their respective abiotic range in the ice interior, with a maximum in the lower part of the ice that did not coincide with the maximum in [chl $a]$.

\section{Discussion}

\subsection{Overview on the dynamic of $\mathrm{O}_{2}$ in comparison to those of Ar and $\mathrm{N}_{2}$}

Since $\mathrm{N}_{2}$ and Ar are only sensitive to physical processes in the present study, the fact that $\mathrm{O}_{2}$ standing stocks varied in the same way as $\mathrm{N}_{2}$ and Ar over time (Fig. 3) indicates that the physical controls on $\mathrm{O}_{2}$ standing stocks dominated over the biological ones. Two main physical processes affect the standing stocks of gases in ice: the incorporation during ice growth and the subsequent gas transport within the ice. Gas incorporation during ice growth would result in similar changes in gas standing stock and ice thickness, while subsequent gas transport within the ice could result in decoupled changes.

Figure 6 compares the changes in gas standing stocks and ice thickness in all the sampling events relative to BRW2. Increasing standing stocks and ice thickness in one sampling event (relative to BRW2) will result in a value of changes above 1 . Further, if the gas standing stocks increased solely due to ice growth, gas standing stocks and ice thickness will show a similar value of changes. Therefore, the changes of gas standing stocks that (almost) evolve in the same way as the ice thickness from BRW2 to BRW7 indicate that gas incorporation was (mainly) associated with ice growth, while the significant differences in BRW8 and BRW10 indicate subsequent gas transport.

Subsequent gas transport may have occurred in BRW8 and BRW10 because both ice cores were permeable (brine volume fraction above $5 \%$ ) at all depths. However, the processes leading to the subsequent gas transport were different in both sampling events, as the changes relative to BRW2 increased in BRW8 for all the gases (indicating an addition of gases), but decreased in BRW10 (indicating a removal of gases), and more particularly for $\mathrm{N}_{2}$ and $\mathrm{Ar}$ than for $\mathrm{O}_{2}$ (Fig. 6).

Therefore, the temporal changes of the standing stocks indicate three distinct stages in the gas dynamics: (1) gas incorporation during ice growth from BRW2 to BRW7, (2) gas accumulation in BRW8 despite the increase of ice permeability at all depths, and (3) gas removal in BRW10, but with larger removal of $\mathrm{Ar}$ and $\mathrm{N}_{2}$ than $\mathrm{O}_{2}$.

\subsection{Gas incorporation during ice growth}

If the entrapment of gases in sea ice was constant during ice growth, we should expect a constant $\left[\mathrm{O}_{2}\right]$ in ice with depth. The slight decreasing $\left[\mathrm{O}_{2}\right]$ in ice from the surface to the bot-

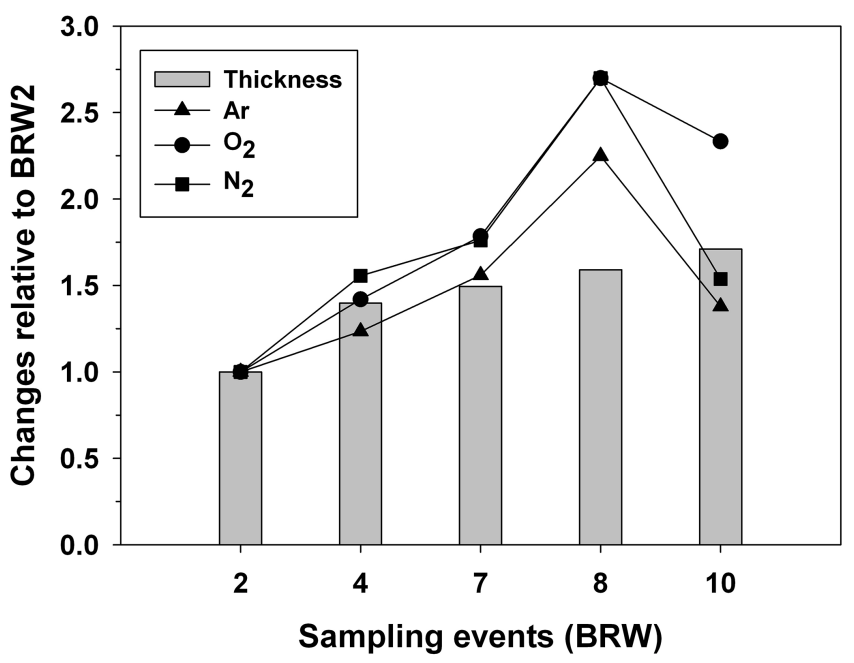

Figure 6. Changes of ice thickness, $\mathrm{Ar}, \mathrm{O}_{2}$ and $\mathrm{N}_{2}$ concentrations for each sampling event relative to BRW2. Value above, equal to or below 1 indicates an observed change that is respectively higher, equal to or lower than the value in BRW2.

tom of the impermeable ice layers ( 2 to $4.9 \%$ of brine volume fraction) (Fig. 5) then indicates a decrease in the entrapment efficiency during ice growth. That decrease in the incorporation efficiency has been suggested for $\mathrm{Ar}$ in Zhou et al. (2013) and is also valid for $\mathrm{CH}_{4}$ (Zhou et al., 2014). Briefly, when sea ice forms, gas concentration increases in parallel with salinity (this is the so-called "brine concentration"). At the same time, because of the temperature gradient at the beginning of ice growth, brine salinity increases above seawater salinity, leading to the decrease of gas solubility in brine. Both increasing gas concentration and decreasing gas solubility lead to gas supersaturation, and eventually gas bubble formation. Whatever the ice depth where gas bubble formation take place, the formed gas bubbles may then ascend due to their buoyancy and accumulate under the impermeable ice layers. Because gas bubbles move upwards due to their buoyancy, while dissolved compounds are subject to gravity drainage (i.e., downward movement), gas bubble formation favors gas accumulation in sea ice in contrast to the dissolved compounds. However, as sea ice thickens, the temperature gradient (i.e., brine salinity gradient) decreases in the ice, and gas bubble formation due to solubility changes becomes less efficient. This mechanism explains the slight decreasing trend in $\left[\mathrm{O}_{2}\right]$ in ice from the surface to the bottom of the impermeable ice layers.

The presence of gas bubbles in the impermeable ice layers is confirmed by ice thin sections (Zhou et al., 2013), and the large $\mathrm{N}_{2}$ supersaturations also indicate the presence of gas bubbles in our ice samples. Indeed, $\mathrm{N}_{2}$ supersaturation reached up to $7000 \%$ in the impermeable ice layers, while supersaturation of $2200 \%$ already corresponds to gas bubble formation (Killawee et al., 1998). 
Because the accumulation of gas bubbles occurred at the beginning of the ice growth, i.e., in the upper ice layers, which are also associated with high brine salinity (hence low gas solubility) and low brine volume fractions at the sampling, it is not surprising to observe high $\mathrm{O}_{2}, \mathrm{Ar}$ and $\mathrm{N}_{2}$ supersaturation at low brine volume fractions (Fig. 4).

\subsection{Gas accumulation subsequent to ice formation}

\subsubsection{Gas bubble formation due to biological activity}

The changes in gas standing stocks that deviated from the changes in ice thickness in BRW8 (relative to BRW2) indicate an addition of gases. The addition of gases may be counter-intuitive because BRW8 was permeable at all depths; hence, gas exchanges (diffusion and/or convection) should tend to alleviate the supersaturation that is formed during ice growth (see previous section), leading to a decrease of the standing stocks, rather than an accumulation of gases as it is observed.

Further, the simultaneous addition of $\mathrm{O}_{2}, \mathrm{Ar}$ and $\mathrm{N}_{2}$ (Fig. S2 in the Supplement) was only possible through gas bubble formation and accumulation in sea ice. Since fulldepth convection occurred in BRW8 (see Sect. 2.1), additional dissolved gases would be drained out of the ice through convection, while additional gas bubbles may remain in the ice due to their buoyancy despite brine convection. The resulting questions are then how do these gas bubbles form in sea ice and how can they accumulate in the permeable ice layers?

One explanation for the accumulation of gas bubbles could be the growth of gas bubbles from pre-existing gas cavities, triggered by local supersaturation fluctuations (Jones et al., 1999). Because $\left[\mathrm{O}_{2}\right]$ in bulk ice was at solubility in the bottom $30 \mathrm{~cm}$ of the ice in BRW2 and BRW4, but became locally supersaturated in BRW7 when [chl $a$ ] increased sharply (Fig. 5), we postulate that biological activity in BRW7 created $\mathrm{O}_{2}$ supersaturation and possibly gas bubbles (Tsurikov, 1979) in some local micro-niches (i.e., confined pores created by microbial excretion and/or structure), forming the so-called "pre-existing gas cavities". Then, the increasing ice permeability and full-depth convection in BRW8 allowed the local supersaturation fluctuation, which favored the growth of gas bubbles (Jones et al., 1999) and supports the observed $\mathrm{O}_{2}$ accumulation. Once the $\mathrm{O}_{2}$ gas bubbles are formed, other dissolved gases (e.g., $\mathrm{N}_{2}$ and Ar) may diffuse from brine into the gas bubbles, because the partial pressure of $\mathrm{N}_{2}$ and Ar in brine is higher than that in the $\mathrm{O}_{2}$ gas bubbles (e.g., Lubetkin, 2003). This process eventually allows the accumulation of all the gases in sea ice, and more particularly $\mathrm{N}_{2}$ rather than $\mathrm{Ar}$ (see the larger changes in $\mathrm{N}_{2}$ than in Ar in Fig. 6), because the partial pressure of $\mathrm{N}_{2}$ is higher than that of $\mathrm{Ar}$ (see the range of $\left[\mathrm{N}_{2}\right]$ and [Ar] in Fig. S2 in the Supplement).

Theoretically, the formed gas bubbles should rise through the brine channels and escape from the permeable ice. The fact that we observed an accumulation of gases in BRW8 indicates that the process of gas bubble escape was not instantaneous. The geometry of the brine network or tortuosity (e.g., Golden et al., 2007), the impurities in brine (Liger-Belair, 2005), the presence of biogenic exopolymer substances (Krembs et al., 2011) and the intensity of brine drainage (Moreau et al., 2014) may all slow down the ascension of gas bubbles through the brine network, i.e., increasing the duration needed for gas equilibrium.

\subsubsection{Void formation in warming sea ice}

Another explanation for gas bubble formation in warming sea ice (BRW 8) is the formation of voids, caused by the melting of the pure ice which has a lower density than brine (Light et al., 2003; Tsurikov, 1979). Although void formation in sea ice inevitably leads to gas exsolution from brine, these voids had to form before brine convection for significant gas bubble formation. Otherwise, brine convection may fill the voids in sea ice, impeding the process of exsolution.

\subsubsection{Superimposed ice formation}

Superimposed ice formation was found in the first $20 \mathrm{~cm}$ of the surface of BRW10 (Zhou et al., 2013), which implies the seepage of snow meltwater and subsequent freezing on contact with sea ice (Haas et al., 2001). The mechanism leading to gas accumulation in or right below the superimposed ice is unclear, but there are three potential explanations for this observation according to Tsurikov (1979): (1) direct input of atmospheric air in the ice pores (because of the positive freeboard) before the formation of the superimposed ice layers, (2) accumulation of gas bubbles that have risen through the brine network, or (3) accumulation of gases associated with the rapid freezing of snow meltwater (see Zhou et al., 2013, for a more extensive discussion).

\subsection{Difference in the changes of standing stocks between $\mathrm{O}_{2}$ and both $\mathrm{Ar}$ and $\mathrm{N}_{2}$}

The changes of the standing stocks (relative to BRW2) decreased between BRW8 and BRW10 (Fig. 6) for all the gases, indicating the removal of gases from sea ice. The fact that both [Ar] and [ $\left.\mathrm{N}_{2}\right]$ dropped to their respective solubility in ice (below the superimposed ice layers) (Fig. S2 in the Supplement) is a result of prolonged gas exchange (through gas bubble escape and gas diffusion). The addition of snow- and ice meltwater likely has further drawn down [Ar] and $\left[\mathrm{N}_{2}\right]$ to below their respective solubility in ice. Previous analyses of water stable isotopes in brine, nitrate concentrations and ice texture (Zhou et al., 2013) support the suggestion of snowand ice-meltwater infiltration.

In the layers comprised between $20 \mathrm{~cm}$ (i.e., below the superimposed ice layer) and $75 \mathrm{~cm}$ of BRW10, [O $\left.\mathrm{O}_{2}\right]$ also approached the saturation as for $\left[\mathrm{N}_{2}\right]$ and $[\mathrm{Ar}]$, indicating that all the gases are likely dissolved in brine. Dividing the 
observed $\left[\mathrm{O}_{2}\right]$ in ice by the brine volume fraction, and assuming a density of the brine of 1 (because brine salinity was close to seawater salinity), we obtain the range of $\left[\mathrm{O}_{2}\right]$ in brine, which range from 232 to $647 \mu \mathrm{mol} \mathrm{kg}{ }^{-1}$, with a mean of $400 \mu \mathrm{mol} \mathrm{kg}^{-1}$. That range is close to that presented in $\mathrm{Pa}-$ padimitriou et al. (2007) $\left(212\right.$ to $\left.604 \mu \mathrm{mol} \mathrm{kg}^{-1}\right)$ where the loss of $\mathrm{O}_{2}$ from ice was also evident.

In contrast to $[\mathrm{Ar}]$ and $\left[\mathrm{N}_{2}\right],\left[\mathrm{O}_{2}\right]$ was supersaturated at the bottom of BRW10 (Fig. S2 in the Supplement), and the changes of $\mathrm{O}_{2}$ standing stocks (relative to BRW2) decreased with a lower magnitude than $\mathrm{Ar}$ and $\mathrm{N}_{2}$ (Fig. 6). The reason is that biological $\mathrm{O}_{2}$ production partly compensated for the loss of $\mathrm{O}_{2}$ due to gas exchange. $\left[\mathrm{O}_{2}\right]$ values higher than the solubility were indeed found in the lower part of BRW10 where high [chl $a$ ] were also observed.

We made a simple calculation to estimate the changes of saturation associated with the biological $\mathrm{O}_{2}$ production between BRW8 and BRW10. Mean Ar solubility in the whole ice column has increased from 1.9 (in BRW8) to $2.8 \mu \mathrm{mol} \mathrm{L}^{-1}$ (in BRW10), i.e., by $50 \%$. Similarly $\mathrm{O}_{2}$ solubility has increased from 38 to $57 \mu \mathrm{mol} \mathrm{L}{ }^{-1}$, i.e., also by $50 \%$. Therefore, in a closed system, the saturation levels of both $\mathrm{Ar}$ and $\mathrm{O}_{2}$ should have decreased by $50 \%$. Meanwhile, mean $\mathrm{Ar}$ saturation has decreased from 263 to $-15 \%$, i.e., by $106 \%$. Hence, the $50 \%$ of changes in Ar solubility are not large enough to explain the changes in the saturation levels, and about $56 \%$ of the decrease in Ar saturation is associated with the escape of gas bubble escape, gas diffusion and possibly the addition of snow meltwater that contributed to the Ar saturation levels down to $-15 \%$. Mean $\mathrm{O}_{2}$ saturation has decreased from 180 to $58 \%$, i.e., by $79 \%$, which was lower than the $106 \%$ observed for Ar. The difference $(106-79 \%=27 \%)$ is likely the contribution of biological activity to the $\mathrm{O}_{2}$ supersaturation.

There is one fundamental difference between BRW8 and BRW10 that is worth discussing: why did biological activity trigger gas accumulation in BRW8, but not in BRW10? One simple reason would be the larger brine volume fraction in the upper layers of BRW10 (10 to $30 \%$ ) in comparison to BRW8 (7.5 to $10 \%$ ), which allowed the evacuation of the formed gas bubbles. Another explanation would be that gas bubbles were more difficult to nucleate in BRW10. Indeed, the production of $\mathrm{O}_{2}$ in BRW8 occurred at the beginning of the increase of ice permeability, when both gas cavities and supersaturated gases were present, and when brine convection allowed the fluctuations of local supersaturations. In contrast, in BRW10, low $\mathrm{N}_{2}$ and Ar supersaturation due to prolonged gas equilibration between the atmosphere and brine (Fig. 4), in combination with brine stratification (i.e, absence of local supersaturation fluctuations due to brine convection), could have made it more difficult to form gas bubbles from $\mathrm{O}_{2}$ production in BRW10.

\subsection{Gas exchange at the bottom of the ice}

Although ice algae produces $\mathrm{O}_{2}$, the maximum of [chl $a$ ] did not coincide with the maximum of $\left[\mathrm{O}_{2}\right]$ over all the sampling events. The low phaeopigment percentage (20-30\%) in those bottom layers (Fig. $5 b$ ) suggests low algal degradation, and hence low consumption of $\mathrm{O}_{2}$ by the heterotrophs in comparison to the algal production. A potential pathway that allows the removal of the produced $\mathrm{O}_{2}$ in these bottom permeable ice layers is the transport through diffusion and convection. The fact that $\left[\mathrm{O}_{2}\right],[\mathrm{Ar}]$, and $\left[\mathrm{N}_{2}\right]$ in ice all reached the solubility in the bottom of the ice supports the suggestion of gas exchange with seawater - where all the gases are assumed to be at saturation.

\subsection{Caveats and uncertainties when calculating NCP from $\mathrm{O}_{2} / \mathrm{Ar}$ with $\mathrm{O}_{2} / \mathrm{N}_{2}$ in sea ice}

Recent studies have determined NCP in seawater, using Ar to correct for the physical contribution in the variation of $\mathrm{O}_{2}$ (Cassar et al., 2009; Castro-Morales et al., 2013; Hendricks et al., 2004; Reuer et al., 2007), while $\mathrm{O}_{2} / \mathrm{N}_{2}$ was shown to be sensitive to the biological activity in basal continental ice (e.g., Souchez et al., 2006). In this section, we will discuss caveats and uncertainties related to the calculation of NCP from $\mathrm{O}_{2} / \mathrm{Ar}$ or $\mathrm{O}_{2} / \mathrm{N}_{2}$ in sea ice.

\subsection{1 $\mathrm{O}_{2} / \mathrm{N}_{2}$ and $\mathrm{O}_{2} / \mathrm{Ar}$ trends in this study}

The range of $\mathrm{O}_{2} / \mathrm{N}_{2}$ from BRW2 to BRW7 (0.27 and 0.41) remained within the abiotic range (0.27-0.51), indicating that we cannot exclude the possibility that these were solely associated with physical processes. Indeed, the observed range is consistent with those obtained from ice growth experiments in abiotic conditions (0.37-0.45) (Killawee et al., 1998), or with negligible bacterial activity (0.32-0.44) (Tison et al., 2002). In contrast, the increase of $\mathrm{O}_{2} / \mathrm{N}_{2}$ up to 1.47 , i.e., beyond the abiotic range, in BRW10, indicates that the contribution of biological activity to the $\left[\mathrm{O}_{2}\right]$ dominated over that of the physical processes. This is in agreement with what we have observed from the changes of gas standing stocks over time (Sect. 4.4).

To the best of our knowledge, $\mathrm{O}_{2} / \mathrm{Ar}$ has never been measured in ice before. However, the range of $\mathrm{O}_{2} / \mathrm{Ar}$ observed in the present study (15.8-97.6) is comparable to (if not higher than) the range of $\mathrm{O}_{2} / \mathrm{Ar}$ in seawater studies (1055) (Nemcek et al., 2008; Shadwick et al., 2014), pointing to the reliability of our results. Further, since $\mathrm{O}_{2} / \mathrm{Ar}$ and $\mathrm{O}_{2} / \mathrm{N}_{2}$ evolve similarly toward higher values over the sampling events, the sharp increase of $\mathrm{O}_{2} / \mathrm{Ar}$ in BRW10 likely indicates, as for $\mathrm{O}_{2} / \mathrm{N}_{2}$, the switch from a situation where the physical contribution to $\mathrm{O}_{2}$ supersaturation dominated to a situation where the biological contribution dominated.

The main difference between $\mathrm{O}_{2} / \mathrm{Ar}$ and $\mathrm{O}_{2} / \mathrm{N}_{2}$ (Fig. 5c, d) was their variability with depth: $\mathrm{O}_{2} / \mathrm{Ar}$ exceeded the 
abiotic range from BRW4 onwards (versus BRW8 for $\mathrm{O}_{2} / \mathrm{N}_{2}$ ). That difference may result from (1) the relative abundance of $\mathrm{O}_{2}$ compared to those of $\mathrm{Ar}$ and $\mathrm{N}_{2}$, (2) the relative solubilities of the gases and (3) the relative diffusion rates of the gases. Firstly, since $\left[\mathrm{O}_{2}\right]$ is about 20 times higher than [Ar], but about 3 times lower than $\left[\mathrm{N}_{2}\right]$, adding the same amount of $\mathrm{O}_{2}$ (due to biological activity) will induce a higher increase in the $\mathrm{O}_{2} / \mathrm{Ar}$ ratio than in the $\mathrm{O}_{2} / \mathrm{N}_{2}$ ratio. Secondly, $\mathrm{N}_{2}$ solubility in brine was clearly different from that of $\mathrm{O}_{2}$ and $\mathrm{Ar}$, as suggested by the larger supersaturation of $\mathrm{N}_{2}$ in comparison to $\mathrm{O}_{2}$ and $\mathrm{Ar}$ (Fig. 4). That difference in gas solubility impacts the partitioning of gases between brine and gas bubbles, which then affect differently the $\mathrm{O}_{2} / \mathrm{Ar}$ and $\mathrm{O}_{2} / \mathrm{N}_{2}$ ratios. Thirdly, although there is currently no consensus on the diffusion coefficient of $\mathrm{O}_{2}, \mathrm{Ar}$, and $\mathrm{N}_{2}$ in brine (Table 1), it is well established that $\mathrm{O}_{2} / \mathrm{Ar}$ and $\mathrm{O}_{2} / \mathrm{N}_{2}$ ratios will change if diffusion occurs in the permeable bottom ice layers (Killawee et al., 1998).

\subsubsection{Biases on $\left[\mathrm{O}_{2}\right]_{\mathrm{eq}} /[\mathrm{Ar}]_{\mathrm{eq}}$ and $\left[\mathrm{O}_{2}\right]_{\mathrm{eq}} /\left[\mathrm{N}_{2}\right]_{\mathrm{eq}}$ due to physical processes}

Before calculating NCP from Eqs. (2) and (3), we first assess the potential biases on NCP associated with the impact of gas diffusion and gas bubble nucleation on $\left[\mathrm{O}_{2}\right]_{\mathrm{eq}} /[\mathrm{Ar}]_{\mathrm{eq}}$ and $\left[\mathrm{O}_{2}\right]_{\mathrm{eq}} /\left[\mathrm{N}_{2}\right]_{\mathrm{eq}}$. The presence of gas bubbles will draw $\left[\mathrm{O}_{2}\right]_{\text {eq }} /[\mathrm{Ar}]_{\text {eq }}$ from 20.48 (solubility in seawater) to 22.5 (ratio in gas bubbles) and $\left[\mathrm{O}_{2}\right]_{\mathrm{eq}} /\left[\mathrm{N}_{2}\right]_{\mathrm{eq}}$ from 0.56 to 0.27 (Sect. 2.4). Gas diffusion privileges the loss of $\mathrm{O}_{2}$ in comparison to $\mathrm{Ar}$ and $\mathrm{N}_{2}$ by a factor of 1.5 and 1.1 respectively, if one considers the ratio of diffusion coefficient following Broecker and Peng (1982). But if one considers the work of Crabeck et al. (2014), the ratio of diffusion coefficient for $\mathrm{O}_{2}$ / Ar will change by a factor of 0.9 to 1.1 and for $\mathrm{O}_{2} / \mathrm{N}_{2}$ by a factor of 0.6 to 0.72 (Table 1). The expected changes (given in percentage in Table 2) thus range from -9.2 to $-33.3 \%$ for $\left[\mathrm{O}_{2}\right]_{\mathrm{eq}} /[\mathrm{Ar}]_{\mathrm{eq}}$ and from -8.9 to $+66 \%$ for $\left[\mathrm{O}_{2}\right]_{\text {eq }} /\left[\mathrm{N}_{2}\right]_{\text {eq }}$ depending on whether we consider the work of Broecker and Peng (1982) or Crabeck et al. (2014). Considering the lower range of bias on $\left[\mathrm{O}_{2}\right]_{\mathrm{eq}} /[\mathrm{Ar}]_{\mathrm{eq}}$ in comparison to $\left[\mathrm{O}_{2}\right]_{\mathrm{eq}} /\left[\mathrm{N}_{2}\right]_{\mathrm{eq}}$, we suggest using the former in the calculation of $\left[\mathrm{O}_{2}\right]_{\text {bio }}$ and NCP.

We estimated the propagation of errors on $\left[\mathrm{O}_{2}\right]_{\text {bio }}$ (calculated from Eq. 3), using the Monte Carlo procedure and neglecting the error on gas diffusion (i.e., assuming equivalent diffusivities for $\mathrm{O}_{2}$ and $\mathrm{Ar}$ in sea ice as in Crabeck et al., 2014). We used random values of the measured parameters ( $T, S$ and $\mathrm{O}_{2} / \mathrm{Ar}$ ) between the mean \pm standard deviation over 1000 iterations, assuming a maximum error of $9.9 \%$ on $\left[\mathrm{O}_{2}\right]_{\mathrm{eq}} /[\mathrm{Ar}]_{\mathrm{eq}}$ due to gas bubble formation and an absolute error of 0.1 for $T$ and $S$ (Table 2). The calculated maximum uncertainty of $\left[\mathrm{O}_{2}\right]_{\text {bio }}$ is then $34 \%$.
Table 2. Synthesis on the trends of changes of $\mathrm{O}_{2} / \mathrm{Ar}$ and $\mathrm{O}_{2} / \mathrm{N}_{2}$ at the ice-water interface. An upward arrow indicates that the process increases the ratio, while a downward arrow indicates that the process decreases the ratio. The percentages in brackets indicate the maximal changes of the ratio associated with the physical processes (see Sect. 4.6.2 for details).

\begin{tabular}{lcc}
\hline & $\mathrm{O}_{2} / \mathrm{Ar}$ & $\mathrm{O}_{2} / \mathrm{N}_{2}$ \\
\hline Photosynthesis & $\uparrow$ & $\uparrow$ \\
Respiration & $\downarrow$ & $\downarrow$ \\
Gas bubble formation & $\uparrow(+9.9 \%)$ & $\downarrow(-51.8 \%)$ \\
Diffusion $^{1}$ & $\downarrow(-33.3 \%)$ & $\downarrow(-8.9 \%)$ \\
Diffusion $^{2}$ & $?(-9.2$ to $+11 \%)$ & $\uparrow(+39$ to $+66 \%)$ \\
\hline
\end{tabular}

${ }^{1}$ Broecker and Peng (1982); ${ }^{2}$ Crabeck et al. (2014)

\subsubsection{Biases on $\left[\mathrm{O}_{2}\right]_{\mathrm{eq}}$ due to physical processes}

Equation (3) implicitly assumes that $\left[\mathrm{O}_{2}\right]$ is equal to $\left[\mathrm{O}_{2}\right]_{\mathrm{eq}}$ in the absence of biological activity. However, as discussed in Sect. 2.5, $\left[\mathrm{O}_{2}\right]_{\text {eq }}$ prior to biological activity may be higher than the gas solubility calculated at in situ temperature and salinity following Garcia and Gordon (1992) and Hamme and Emerson (2004), because of gas bubble accumulation (Sect. 4.2). Indeed, Ar supersaturation approached $500 \%$ for brine volume fraction of $5 \%$ (the transition from permeable to impermeable layers) (Fig. 4) - in comparison to $1 \%$ of supersaturation reported in seawater studies (Hamme and Severinghaus, 2007), and $564 \%$ in Antarctic lake ice (Hood et al., 1998). Similarly, $\left[\mathrm{O}_{2}\right]_{\mathrm{eq}}$ at sea ice consolidation may be supersaturated as well: at least $500 \%$ if we assume similar solubility for $\mathrm{O}_{2}$ and $\mathrm{Ar}$ (Weiss, 1970), and even more if we take into account the $\mathrm{O}_{2}$ production in the bottom ice layers.

\subsection{Estimate of $\left[\mathrm{O}_{2}\right]_{b i o}$ and $\mathrm{NCP}$ and in sea ice}

\subsubsection{The impermeable layers}

Previous sections have shown how physical processes and biological activity both influence $\left[\mathrm{O}_{2}\right]$ in sea ice. Therefore, $\mathrm{NCP}$ calculations from $\left[\mathrm{O}_{2}\right]$ require removing the physical imprints. Since we assume that the impermeable ice layers are closed systems, only biological activity could change $\mathrm{O}_{2}$ concentration in these layers over time. Thus, theoretically, the changes of the standing stocks of $\mathrm{O}_{2}$ in the impermeable layers $(0-50 \mathrm{~cm})$ from BRW2 to BRW7 (Table $3-\mathrm{O}_{2}$ meth. column) should be equal to NCP. However, since BRW2, BRW4 and BRW7 refer to different sampled ice cores, rather than the changes in the same ice core over time, spatial variability affects the calculated NCPs. For instance, the simultaneous drop in $\left[\mathrm{O}_{2}\right],[\mathrm{Ar}]$ and $\left[\mathrm{N}_{2}\right]$ to the solubility values in BRW4, between 20 and $40 \mathrm{~cm}$ depth (Fig. S2 in the Supplement), points to spatial variability rather than NCP changes. That spatial variability was likely associated with changes in water masses, as water stable isotopes also showed anomalies at the same ice depths (Zhou et al., 2013). NCP calculated 
Table 3. NCP in the impermeable ice layers ( 0 to $50 \mathrm{~cm}$ depth) from BRW2 to BRW4 and from BRW4 to BRW7, in $\mu$ mol $\mathrm{O}_{2} \mathrm{~L}^{-1} \mathrm{~d}^{-1}$. The columns entitled " $\mathrm{O}_{2}$ meth." refer to the NCP derived from the standing stocks of $\left[\mathrm{O}_{2}\right]$ in bulk ice, while the columns entitled " $\mathrm{O}_{2} /$ Ar" refer to the NCP derived using the $\mathrm{O}_{2} / \mathrm{Ar}$ (see Eqs. 2 and 3 , considering 500 to $3000 \%$ of supersaturation). The latter could be further affected by a maximum uncertainty of $35 \%$ (see Sect. 4.6.2).

\begin{tabular}{lrrrrr}
\hline & \multicolumn{2}{c}{ BRW2-BRW4 } & & \multicolumn{2}{c}{ BRW4-BRW7 } \\
\cline { 2 - 3 } \cline { 5 - 6 } Ice depth (cm) & $\mathrm{O}_{2}$ meth. & $\mathrm{O}_{2}$ / Ar meth. & & $\mathrm{O}_{2}$ meth. & $\mathrm{O}_{2}$ / Ar meth. \\
\hline $0-10$ & 1.0 & $0-0.1$ & & -1.2 & $0.6-3.6$ \\
$10-20$ & 1.9 & $-0.1-0$ & & -4.3 & $-0.2-1.3$ \\
$20-30$ & 0.4 & $-0.1-0$ & & 4.9 & $0.2-1.0$ \\
$30-40$ & 2.0 & $0-0.3$ & & -6.6 & $-0.6-3.3$ \\
$40-50$ & 1.5 & $0-0.2$ & & -3.9 & $-3.3-0.5$ \\
\hline
\end{tabular}

following Eq. (3) should then correct for spatial variability, because it corrects for $\mathrm{O}_{2}$ variations using $\mathrm{Ar}$, which evolved under the same physical conditions (i.e., experiencing the same spatial variability).

We further multiplied the NCP (calculated following Eq. 3) by a factor of 5 to 30 to take into account the full range of observed $\mathrm{O}_{2}$ supersaturation when the ice became impermeable (Fig. 4 and Sect. 4.6.3). Dividing the obtained values by the number of days between the sampling events then provides NCP (Table $3-\mathrm{O}_{2} / \mathrm{Ar}$ meth.). Note that, as demonstrated in Sect. 4.6.2, these ranges have a maximum uncertainty of $40 \%$ due to the impact of physical processes on $\left[\mathrm{O}_{2}\right]_{\mathrm{eq}} /[\mathrm{Ar}]_{\mathrm{eq}}(34 \%$, Sect. 4.6.2) and the sampling time (up to $6 \%$, Sect. 2.3 and S1 in the Supplement).

Both positive and negative NCP from BRW4 to BRW7 indicate that heterotrophic and autotrophic processes coexist in sea ice; this is possible due to the presence of micro-niches in sea ice (Rysgaard et al., 2008). The change from a net autotrophic (BRW2-BRW4) to a both autotrophic and heterotrophic system (BRW4-BRW7) is also in agreement with previous results suggesting increased remineralization (i.e., net heterotrophic processes) in BRW7 (Zhou et al., 2013).

Measurements of NCP in the ice interior are scarce, which limit the comparison of our values with the literature. However, the positive NCPs reported here $(0$ to $3.6 \mu \mathrm{mol} \mathrm{O}_{2} \mathrm{~L}^{-1} \mathrm{~d}^{-1}$, which are equivalent to 0 to $1.3 \mathrm{mg} \mathrm{C} \mathrm{m}^{-3} \mathrm{~h}^{-1}$ ) are consistent with those measured in the melt ponds in the Canada Basin in 2005 (0.03 and $2.12 \mathrm{mg} \mathrm{C} \mathrm{m}^{-3} \mathrm{~h}^{-1}$ ) (Lee et al., 2012), with similar [chl $a$ ] (0.02 and $0.7 \mathrm{mg} \mathrm{chl} a \mathrm{~m}^{-3}$ in the present study versus 0.1 and $0.6 \mathrm{mg} \mathrm{chl} a \mathrm{~m}^{-3}$ in Lee et al. 2012). The negative NCPs $\left(-0.2\right.$ to $\left.-6.6 \mu \mathrm{mol} \mathrm{O}_{2} \mathrm{~L}^{-1} \mathrm{~d}^{-1}\right)$ are comparable to the range of $\mathrm{O}_{2}$ consumption rates measured in the bottom of sea ice in Franklin Bay (0 to $3 \mu \mathrm{mol} \mathrm{O} \mathrm{L}^{-1} \mathrm{~d}^{-1}$ ) (Rysgaard et al., 2008).

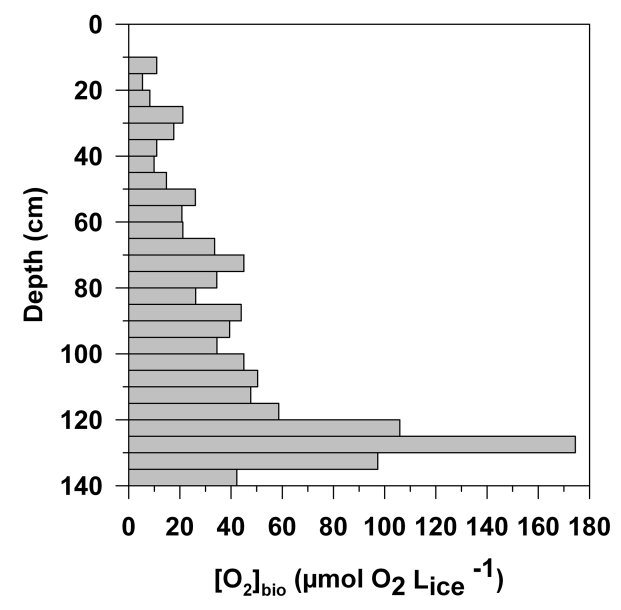

Figure 7. $\left[\mathrm{O}_{2}\right]_{\text {bio }}$ in BRW10 calculated following Eq. (3). The results may be converted into $\mathrm{C}$ uptake, assuming a photosynthetic quotient $\mathrm{O}_{2} / \mathrm{C}$ of 1.43 (Glud et al., 2002).

\subsubsection{The permeable layers}

In the permeable layers, $\left[\mathrm{O}_{2}\right]_{\text {eq }}$ should be closer to the gas solubility calculated at in situ temperature and salinity following Garcia and Gordon (1992) than in the impermeable layers. However, brine convection and diffusion may have affected $\left[\mathrm{O}_{2}\right]_{\text {eq }} /[\mathrm{Ar}]_{\text {eq }}$. Beside the fact that a large range of diffusion coefficients exist in the literature (Table 1), our present understanding of brine dynamics and gas transport does not allow assessing the frequency or the impact of the convection on the variations of $\left[\mathrm{O}_{2}\right]$ over the sampling period (e.g., not in BRW8). Therefore, rather than calculating NCP based on the change of $\left[\mathrm{O}_{2}\right]$ between BRW8 and BRW10, and neglecting the differential impact of brine convection and permeability on $\left[\mathrm{O}_{2}\right]$ in both sampling events (Sect. 4.4), we simply provide a conservative estimate of $\left[\mathrm{O}_{2}\right]_{\text {bio }}$ in BRW10, where brine convection was absent and, hence, when only biological activity and diffusion took place.

In contrast to the impermeable layers, we simply consider $\left[\mathrm{O}_{2}\right]_{\text {eq }}$ at saturation (hence no supersaturation), since all the gas bubbles have escaped from the ice (Sect. 4.4). The maximum uncertainty is $21 \%$ : this was calculated following the procedure described in Sect. 4.6.2, but neglecting the 9.9\% of error due to gas bubble accumulation (because of the absence of gas bubbles), and adding the $6 \%$ of error due to diel $\mathrm{O}_{2}$ production/respiration.

The calculated $\left[\mathrm{O}_{2}\right]_{\text {bio }}$ in ice varies between 5.4 and $174.5 \mu \mathrm{mol} \mathrm{O}_{2} \mathrm{~L}^{-1}$ (Fig. 7), which is equivalent to a carbon uptake (or autotrophic organic carbon production) of 3.8 to $122 \mu \mathrm{mol} \mathrm{C} \mathrm{L}{ }^{-1}$, considering the $\mathrm{O}_{2} / \mathrm{C}$ ratio of 1.43 (Glud et al., 2002). This minimum estimate is comparable to the range of POC found in the bottom of Barrow sea ice, in May (105 to $212 \mu \mathrm{mol} \mathrm{C} \mathrm{L}^{-1}$ ) (Juhl et al., 2011).

Integrating $\left[\mathrm{O}_{2}\right]_{\text {bio }}$ leads to a standing stock of $52.3 \mathrm{mmol} \mathrm{O}_{2} \mathrm{~m}^{-2}$ due to biological activity, which is 
equivalent to $36.6 \mathrm{mmol} \mathrm{Cm}^{-2}$, or $438.9 \mathrm{mg} \mathrm{C} \mathrm{m}^{-2}$. This fits within the range of integrated sea-ice $\mathrm{POC}$ reported in the Chukchi and Beaufort seas during May/June 2002 (200-2000 $\mathrm{mg} \mathrm{C} \mathrm{m}^{-2}$ ) (Gradinger, 2009). Given that the chl $a$ standing stocks were $8.3 \mathrm{mg} \mathrm{m}^{-2}$ (Zhou et al., 2013), our calculation provides a $\mathrm{C}: \mathrm{Chl} a$ ratio of 52, which compares well with the 57 used in Jin et al. (2006) and obtained from their observations (M. Jin, personal communication, 2014). The consistency of $\mathrm{C}: \operatorname{chl} a$ with the literature and the similarity between $\left[\mathrm{O}_{2}\right]_{\text {bio }}$ with POC in the literature, in spite of neglecting diffusion, suggest that diffusion occurred at a much lower rate than NCP.

\section{Conclusion and perspectives}

We presented the first time series of $\mathrm{O}_{2}, \mathrm{Ar}$ and $\mathrm{N}_{2}$ measurements in natural landfast sea ice, collected in Barrow from February through June 2009. The gases were extracted from ice crushing - a technique that allows the measurement of $\mathrm{O}_{2}$ from both brine and gas bubbles, both in impermeable and permeable layers. The results thus extend our current knowledge, which is limited to dissolved $\mathrm{O}_{2}$ in the bottom permeable ice layers.

We have highlighted three distinct stages in the dynamic of $\mathrm{O}_{2}$ as compared to Ar and $\mathrm{N}_{2}$ : (1) gas incorporation in the form of gas bubbles or dissolved gases. In the latter situation, gas standing stocks increase with increasing ice thickness; (2) gas accumulation subsequent to ice growth, through the formation of gas bubbles due to biological activity, voids and superimposed ice; (3) gas removal due to prolonged gas exchange in permeable ice layers. However, the gas removal was less marked for $\mathrm{O}_{2}$ than for $\mathrm{Ar}$ and $\mathrm{N}_{2}$, because biological $\mathrm{O}_{2}$ production partly compensated for the loss of $\mathrm{O}_{2}$ due to gas exchange (gas bubble escape and gas diffusion).

The dynamics of $\mathrm{O}_{2}$ in landfast sea ice was highly sensitive to physical processes: gas incorporation and subsequent transport. Brine concentration and decreasing solubility (associated with decreasing temperature and increasing brine salinity) cause a nonlinear relationship between gas saturation levels and brine volume fraction. In particular, supersaturations of $\mathrm{O}_{2}$ up to $500 \%$ were still observed in the permeable layers (where brine volume fraction exceeds $5 \%$ ), probably due to the formation of gas bubbles and/or slow gas equilibrium. It still remains unclear how $\mathrm{O}_{2}$ supersaturation affects the $\mathrm{O}_{2}$ dissolved in brine and its diffusion at the icewater interface, but solving this issue will be crucial for the estimate of $\mathrm{NCP}$ based on $\mathrm{O}_{2}$ diffusion; e.g., under-ice eddy covariance (Long et al., 2012), and $\mathrm{O}_{2}$ optode measurements (Mock et al., 2002).

Finally, we discussed the possibility of correcting for the physical imprints (including spatial variability) on $\mathrm{O}_{2}$ variations using $\mathrm{Ar}$ and $\mathrm{N}_{2}$. The main problem associated with gas measurements in sea ice is the uncertainty of gas exchange within the permeable sea ice. $\left[\mathrm{O}_{2}\right]_{\mathrm{eq}}$ upon sea ice consoli- dation is indeed uncertain. Also, the wide range of diffusion coefficients for $\mathrm{O}_{2}$, Ar and $\mathrm{N}_{2}$ found in the literature, and the uncertainty of how both brine convection and diffusion affect the $\mathrm{O}_{2}$ / Ar signal in sea ice have to be solved for accurate NCP estimates. We acknowledge the limitations of our pioneering study, but as our conservative estimate of NCP and $\left[\mathrm{O}_{2}\right]_{\text {bio }}$ are comparable to the literature, NCP calculation using $\mathrm{O}_{2} / \mathrm{Ar}$ appear promising - especially in cases like BRW10, where brine convection was absent and diffusion probably negligible in comparison to NCP.

\section{The Supplement related to this article is available online at doi:10.5194/bg-11-5007-2014-supplement.}

Acknowledgements. The authors would like to thank Hajo Eicken, the rest of the sea ice group of the Geophysical Institute of the University of Alaska Fairbanks, Nicolas-Xavier Geilfus, Gauthier Carnat, Tim Papakyriakou, Bernard Heinesch, Michel Yernaux, Thomas Goossens, Noémie Carnat and Rodd Laing for their help in field work. We are indebted to the Barrow Arctic Science Consortium and the North Slope Borough for their logistical support. We also thank Saïda El Amri for her efficient help in laboratory work, Neige Egmont for her comments and Roberta Hamme for sharing the matlab script on gas diffusion. This research was supported by the F.R.S-FNRS (contract 2.4584.09), the National Science Foundation (project OPP-0632398 (SIZONet)), the University of Alaska Fairbanks and the Belgian Science Policy (contract SD/CA/03A), the NCE ArcticNet and National Science and Engineering Research Council (NSERC). F. Brabant was a research fellow of F.R.S.-FRIA, J. Zhou a research fellow of F.R.S.-FNRS, and B. Delille, a research associate of F.R.S.-FNRS. This is MARE contribution no. 277.

Edited by: T. Treude

\section{References}

Arar, E. J. and Collins, G. B.: In vitro Determination of Chlorophyll $a$ and Pheophytin a in Marine and Freshwater Algae by Fluorescence (Method 445.0), National Exposure Research Laboratory - US Environmental Protection Agency, Ohio, 1997.

Arrigo, K. R., Mock, T., and Lizotte, M. P.: Primary Producers and Sea Ice, in: Sea ice, edited by: Thomas, D. N. and Dieckmann, G. S., Blackwell Publishing Ltd, UK, 2010.

Brierley, A. S. and Thomas, D. N.: Ecology of Southern Ocean pack ice, Adv. Mar. Biol., 43, 171-276, 2002.

Broecker, W. S. and Peng, T. H.: Gas exchange rates between air and sea, Tellus, 26, 21-35, 1974.

Broecker, W. S. and Peng, T.: Tracers in the Sea, The LamontDoherty Geological Observatory, Columbia University, New York, 1982.

Cassar, N., Barnett, B., Bender, M. L., Kaiser, J., Hamme, R. C., and Tilbrook, B.: Continuous high-frequency dissolved $\mathrm{O}_{2} / \mathrm{Ar}$ measurements by Equilibrator Inlet Mass Spectrometry (EIMS), Anal. Chem., 81, 1855-1864, 2009. 
Castro-Morales, K., Cassar, N., Shoosmith, D. R., and Kaiser, J.: Biological production in the Bellingshausen Sea from oxygento-argon ratios and oxygen triple isotopes, Biogeosciences, 10, 2273-2291, doi:10.5194/bg-10-2273-2013, 2013.

Crabeck, O., Delille, B., Rysgaard, S., Thomas, D. N., Geilfus, N. X., Else, B., and Tison, J.-L.: First "in situ" determination of gas transport coefficient $\left(\mathrm{DO}_{2}, \mathrm{DAr}, \mathrm{DN}_{2}\right)$ from bulk gas concentration measurements $\left(\mathrm{O}_{2}, \mathrm{~N}_{2}, \mathrm{Ar}\right)$ in natural sea ice, J. Geophys. Res.-Oceans, in press, 2014.

Craig, H. and Hayward, T.: Oxygen Supersaturation in the Ocean: Biological Versus Physical Contributions, Science, 235, 199202, 1987.

Ferrell, R. T. and Himmelblau, D. M.: Diffusion coefficients of nitrogen and oxygen in water, J. Chem. Eng. Data, 12, 111-115, 1967.

Garcia, H. E. and Gordon, L. I.: Oxygen solubility in seawater: Better fitting equations, Limnol. Oceanogr., 37, 1307-1312, 1992.

Glud, R. N., Rysgaard, S., and Kuhl, M.: A laboratory study on O-2 dynamics and photosynthesis in ice algal communities: quantification by microsensors, O-2 exchange rates, C-14 incubations and a PAM fluorometer, Aquat. Microb. Ecol., 27, 301-311, 2002.

Golden, K. M., Ackley, S. F., and Lytle, V. I.: The percolation phase transition in sea ice, Science, 282, 2238-2241, 1998.

Golden, K. M., Eicken, H., Heaton, A. L., Miner, J., Pringle, D. J., and Zhu, J.: Thermal evolution of permeability and microstructure in sea ice, Geophys. Res. Lett., 34, L16501, doi:10.1029/2007GL030447, 2007.

Gradinger, R.: Sea-ice algae: Major contributors to primary production and algal biomass in the Chukchi and Beaufort Seas during May/June 2002, Deep-Sea Res. Pt. II, 56, 1201-1212, 2009.

Haas, C., Thomas, D. N., and Bareiss, J.: Surface properties and processes of perennial Antarctic sea ice in summer, J. Glaciol., 47, 613-625, 2001.

Hamme, R. C. and Emerson, S. R.: The solubility of neon, nitrogen and argon in distilled water and seawater, Deep-Sea Res. Pt. I, 51, 1517-1528, 2004.

Hamme, R. C. and Severinghaus, J. P.: Trace gas disequilibria during deep-water formation, Deep-Sea Res. Pt. I, 54, 939-950, 2007.

Hendricks, M. B., Bender, M. L., and Barnett, B. A.: Net and gross $\mathrm{O}_{2}$ production in the southern ocean from measurements of biological $\mathrm{O}_{2}$ saturation and its triple isotope composition, DeepSea Res. Pt. I, 51, 1541-1561, 2004.

Hood, E. M., Howes, B. L., and Jenkins, W. J.: Dissolved gas dynamics in perennially ice-covered Lake Fryxell, Antarctica, Limnol. Oceanogr., 43, 265-272, 1998.

Jähne, B., Heinz, G., and Dietrich, W.: Measurement of the diffusion coefficients of sparingly soluble gases in water, J. Geophys. Res.-Oceans, 92, 10767-10776, 1987.

Jin, M., Deal, C. J., Wang, J., Shin, K.-H., Tanaka, N., Whitledge, T. E., Lee, S. H., and Gradinger, R. R.: Controls of the landfast ice-ocean ecosystem offshore Barrow, Alaska, Ann. Glaciol., 44, 63-72, 2006.

Jones, S. F., Evans, G. M., and Galvin, K. P.: Bubble nucleation from gas cavities - a review, Adv. Colloid. Interfac., 80, 27-50, 1999.

Juhl, A. R., Krembs, C., and Meiners, K. M.: Seasonal development and differential retention of ice algae and other organic fractions in first-year Arctic sea ice, Mar. Ecol.-Prog. Ser., 436, 1-16, 2011.

Killawee, J. A., Fairchild, I. J., Tison, J. L., Janssens, L., and Lorrain, R.: Segregation of solutes and gases in experimental freezing of dilute solutions: Implications for natural glacial systems, Geochim. Cosmochim. Ac., 62, 3637-3655, 1998.

Krembs, C., Eicken, H., and Deming, J. W.: Exopolymer alteration of physical properties of sea ice and implications for ice habitability and biogeochemistry in a warmer Arctic, P. Natl. Acad. Sci., 108, 3653-3658, 2011.

Lee, S. H., Stockwell, D. A., Joo, H.-M., Son, Y. B., Kang, C.-K., and Whitledge, T. E.: Phytoplankton production from melting ponds on Arctic sea ice, J. Geophys. Res.-Oceans, 117, C04030, doi:10.1029/2011JC007717, 2012.

Liger-Belair, G.: The Physics and Chemistry behind the Bubbling Properties of Champagne and Sparkling Wines: A State-of-theArt Review, J. Agr. Food Chem., 53, 2788-2802, 2005.

Light, B., Maykut, G., and Grenfell, T.: Effects of temperature on the microstructure of first-year Arctic sea ice, J. Geophys. Res.Oceans, 108, 3051, doi:10.1029/2001JC000887, 2003.

Long, M. H., Koopmans, D., Berg, P., Rysgaard, S., Glud, R. N., and Søgaard, D. H.: Oxygen exchange and ice melt measured at the ice-water interface by eddy correlation, Biogeosciences, 9, 1957-1967, doi:10.5194/bg-9-1957-2012, 2012.

Loose, B., Schlosser, P., Perovich, D., Ringelberg, D., Ho, D. T., Takahashi, T., Richter-Menge, J., Reynolds, C. M., Mcgillis, W. R., and Tison, J. L.: Gas diffusion through columnar laboratory sea ice: implications for mixed-layer ventilation of $\mathrm{CO}_{2}$ in the seasonal ice zone, Tellus B, 63, 23-39, 2010.

Lubetkin, S. D.: Why Is It Much Easier To Nucleate Gas Bubbles than Theory Predicts?, Langmuir, 19, 2575-2587, 2003.

McMinn, A. and Ashworth, C.: Use of oxygen microelectrodes to determine the net production by an Antarctic sea ice algal community, Antarct. Sci., 10, 39-44, 1998.

Michel, C., Legendre, L., Ingram, R. G., Gosselin, M., and Levasseur, M.: Carbon budget of sea-ice algae in spring: Evidence of a significant transfer to zooplankton grazers, J. Geophys. Res., 101, 18345-18360, 1996.

Mock, T., Dieckmann, G. S., Haas, C., Krell, A., Tison, J. L., Belem, A. L., Papadimitriou, S., and Thomas, D. N.: Micro-optodes in sea ice: a new approach to investigate oxygen dynamics during sea ice formation, Aquat. Microb. Ecol., 29, 297-306, 2002.

Moreau, S., Vancoppenolle, M., Zhou, J., Tison, J.-L., Delille, B., and Goosse, H.: Modelling argon dynamics in first-year sea ice, Ocean Model, 73, 1-18, 2014.

Nemcek, N., Ianson, D., and Tortell, P. D.: A high-resolution survey of $\mathrm{DMS}, \mathrm{CO}_{2}$, and $\mathrm{O}_{2} / \mathrm{Ar}$ distributions in productive coastal waters, Global Biogeochem. Cy., 22, GB2009, doi:10.1029/2006GB002879, 2008.

Papadimitriou, S., Thomas, D. N., Kennedy, H., Haas, C., Kuosa, H., Krell, A., and Dieckmann, G. S.: Biogeochemical composition of natural sea ice brines from the Weddell Sea during early austral summer, Limnol. Oceanogr., 52, 1809-1823, 2007.

Raynaud, D., Delmas, R., Ascencio, J. M., and Legrand, M.: Gas extraction from polar ice cores: a critical issue for studying the evolution of atmospheric $\mathrm{CO}_{2}$ and ice-sheet surface elevation, Ann. Glaciol., 3, 265-268, 1982.

Reuer, M. K., Barnett, B. A., Bender, M. L., Falkowski, P. G., and Hendricks, M. B.: New estimates of Southern Ocean biological 
production rates from $\mathrm{O}_{2} / \mathrm{Ar}$ ratios and the triple isotope composition of $\mathrm{O}_{2}$, Deep-Sea Res. Pt. I, 54, 951-974, 2007.

Rysgaard, S., Glud, R. N., Sejr, M. K., Blicher, M. E., and Stahl, H. J.: Denitrification activity and oxygen dynamics in Arctic sea ice, Polar Biol., 31, 527-537, 2008.

Shadwick, E. H., Tilbrook, B., Cassar, N., Trull, T. W., and Rintoul, S. R.: Summertime physical and biological controls on $\mathrm{O}_{2}$ and $\mathrm{CO}_{2}$ in the Australian Sector of the Southern Ocean, J. Marine Syst., online first, doi:10.1016/j.jmarsys.2013.12.008, 2014.

Skoog, D. A., West, D. M., and Holler, F. J.: Chimie analytique, De Boeck Université, Paris, Bruxelles, 1997.

Souchez, R., Jouzel, J., Landais, A., Chappellaz, J., Lorrain, R., and Tison, J. L.: Gas isotopes in ice reveal a vegetated central Greenland during ice sheet invasion, Geophys. Res. Lett., 33, L24503, doi:10.1029/2006GL028424, 2006.

Stefels, J., Carnat, G., Dacey, J. W. H., Goossens, T., Elzenga, J. T. M., and Tison, J. L.: The analysis of dimethylsulfide and dimethylsulfoniopropionate in sea ice: Dry-crushing and melting using stable isotope additions, Mar. Chem., 128-129, 34-43, 2012 .
Thomas, D. N. and Dieckmann, G. S.: Antarctic Sea Ice-a Habitat for Extremophiles, Science, 295, 641-644, 2002.

Tison, J. L., Haas, C., Gowing, M. M., Sleewagen, S., and Bernard, A.: Tank study of physico-chemical controls on gas content and composition during growth of young sea-ice, J. Glaciol., 48, 267-278, 2002.

Tsurikov, V.: The formation and composition of the gas content of sea ice, J. Glaciol., 22, 67-81, 1979.

Weeks, W. F.: On sea ice, University of Alaska Press, Fairbanks, Alaska, 2010.

Weiss, R. F.: The solubility of nitrogen, oxygen and argon in water and seawater, Deep-Sea Res., 17, 721-735, 1970.

Zhou, J., Delille, B., Eicken, H., Vancoppenolle, M., Brabant, F., Carnat, G., Geilfus, N.-X., Papakyriakou, T., Heinesch, B., and Tison, J.-L.: Physical and biogeochemical properties in landfast sea ice (Barrow, Alaska): Insights on brine and gas dynamics across seasons, J. Geophys. Res.-Oceans, 118, 3172-3189, 2013.

Zhou, J., Tison, J.-L., Carnat, G., Geilfus, N.-X., and Delille, B.: Physical controls on the storage of methane in landfast sea ice, The Cryosphere, 8, 1019-1029, doi:10.5194/tc-8-10192014, 2014. 